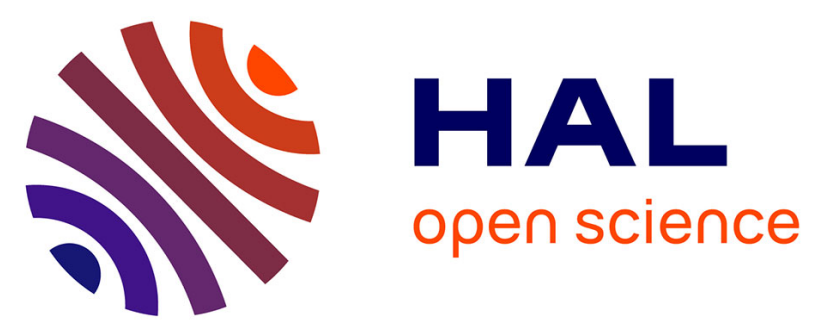

\title{
Real-Time Control of the Enantioselectivity of a Supramolecular Catalyst Allows Selecting the Configuration of Consecutively Formed Stereogenic Centers
}

Jeremy M Zimbron, Xavier Caumes, Yan Li, Christophe M Thomas, Matthieu Raynal, Laurent Bouteiller

\section{To cite this version:}

Jeremy M Zimbron, Xavier Caumes, Yan Li, Christophe M Thomas, Matthieu Raynal, et al. Real-Time Control of the Enantioselectivity of a Supramolecular Catalyst Allows Selecting the Configuration of Consecutively Formed Stereogenic Centers. Angewandte Chemie, 2017, 10.1002/ange.201706757 . hal-01611679

\section{HAL Id: hal-01611679 \\ https://hal.sorbonne-universite.fr/hal-01611679}

Submitted on 6 Oct 2017

HAL is a multi-disciplinary open access archive for the deposit and dissemination of scientific research documents, whether they are published or not. The documents may come from teaching and research institutions in France or abroad, or from public or private research centers.
L'archive ouverte pluridisciplinaire HAL, est destinée au dépôt et à la diffusion de documents scientifiques de niveau recherche, publiés ou non, émanant des établissements d'enseignement et de recherche français ou étrangers, des laboratoires publics ou privés. 


\title{
Real-time control of the enantioselectivity of a supramolecular catalyst allows selecting the configuration of consecutively formed stereogenic centres
}

\author{
Jeremy M. Zimbron, Xavier Caumes, Yan Li, Christophe M. Thomas, Matthieu Raynal, ${ }^{\star}$ and Laurent \\ Bouteiller
}

\begin{abstract}
The enantiomeric state of a supramolecular copper catalyst can be switched in situ in ca. five seconds. The dynamic property of the catalyst is provided by the non-covalent nature of the helical assemblies supporting the copper centres. These assemblies are formed by mixing an achiral benzene-1,3,5-tricarboxamide (BTA) phosphine ligand (for copper coordination) and both enantiomers of a chiral phosphine-free BTA co-monomer (for chirality amplification). The enantioselectivity of the hydrosilylation reaction is fixed by the BTA enantiomer in excess, which can be altered by simple BTA addition. As a result of the complete and fast stereochemical switch, any combination of the enantiomers was obtained during the conversion of a mixture of two substrates.
\end{abstract}

Dynamic and stimuli-responsive catalysts potentially allow tuning their performance during a chemical process. ${ }^{[1]}$ These catalysts can be switched between different states by means of a suitable input (i.e. light, redox, thermal or chemical) with a significant impact on reaction rate, ${ }^{[1]}$ substrate selectivity ${ }^{[2]}$ or diastereoselectivity. ${ }^{[3]} \quad$ Conversely, inverting the enantioselectivity of a single catalyst during a reaction remains an elusive goal despite the promising perspectives of using such a catalyst to select the desired diastereoisomer in one pot stereoselective cascade reactions ${ }^{[4]}$ or to control the tacticity of stereoblock copolymers. ${ }^{[5]}$

In fact, both enantiomers of a product can be obtained from the same catalyst ${ }^{[6]}$ in a predictable manner by connecting a catalytic unit to a chiroptical switch. ${ }^{[7]}$ However, the switch is commonly performed before the catalytic experiment. ${ }^{[8]}$ Controlling the enantiomeric state of a single catalyst in situ ${ }^{[0]}$ faces additional challenges: i) the catalytic system should be dynamic in the conditions of the catalytic reaction, ii) the stereochemical switch should be fast and lead to opposite chiral environments and, iii) the input should preserve the integrity of the catalyst. These

[*] Dr. X. Caumes, Y. Li, Dr. M. Raynal, Dr. L. Bouteiller

Sorbonne Universités,

UPMC Univ Paris 06, CNRS,

Institut Parisien de Chimie Moléculaire,

Equipe Chimie des Polymères,

4 Place Jussieu, F-75005 Paris, France

E-mail : matthieu.raynal@upmc.fr

Dr. J. M. Zimbron, Dr. C. M. Thomas

Chimie ParisTech,

PSL Research University, CNRS,

Institut de Recherche de Chimie Paris, 75005 Paris, France.

Supporting information for this article is given via a link at the end of the document. issues are particularly significant in the case of metal-catalysed reactions since the presence of the metal centre may impede the efficiency and the dynamics of the chiroptical switch. ${ }^{[10]}$ Previous attempts to switch the enantioselectivity in situ were also hampered by the poor stability of the metal catalysts or reactants when exposed to an oxidizing agent ${ }^{[9]}$ or to ultraviolet light. ${ }^{[7 \mathrm{~g}]}$ Based on our previous design of catalysts supported on supramolecular helices, ${ }^{[11]}$ we now describe a strategy which allows to control in real time the enantioselectivity displayed by intrinsically achiral phosphine-copper complexes located at the periphery of a chirally-amplified ${ }^{[12]}$ supramolecular polymer platform. This approach relies on the complete and fast stereochemical switch of the handedness of the dynamic helices producing enantiomeric catalytic centres.

Benzene 1,3,5-tricarboxamide (BTA) monomers have been selected given their chirality amplification properties and their fast dynamics. ${ }^{[13]}$ As shown in Scheme 1, we used supramolecular BTA polymers composed of three types of monomers, two enantiopure co-monomers of opposite configuration and one phosphine-functionalized achiral monomer (for copper coordination). Thanks to chirality amplification effects, homochiral helices are expected to be formed even though the polymers are composed of a scalemic mixture of enantiomers and of achiral monomers. Thus, dual stereocontrol of the asymmetric reaction should be possible by in situ addition of one of the enantiopure co-monomers to invert the handedness of the supramolecular helices (Scheme 1).

We chose the copper-catalysed hydrosilylation of prochiral aromatic ketones using 1-(4-nitrophenyl)ethanone (NPnone) as model substrate, because of the wide scope of reactions catalyzed by phosphine copper hydride species, ${ }^{[14]}$ that include stereoselective cascade transformations. ${ }^{[15]}$ We first mixed BTA $^{\text {PPh2 }}$ (6.0 mol\%), an enantiopure BTA co-monomer (6.6 mol\%) and $\mathrm{Cu}(\mathrm{OAc})_{2} \cdot \mathrm{H}_{2} \mathrm{O}(3.0 \mathrm{~mol} \%)$ at $20^{\circ} \mathrm{C}$ using $\mathrm{PhSiH}_{3}$ as the silane source (Table 1). We found that significant enantiomeric excesses $(47 \%<$ e.e. $<54 \%)$ were obtained with BTA co-monomers having a branched alkyl chain attached to the stereogenic centre. Notably, BTA (S)-Cha and BTA (R)-Cha provided the hydrosilylation product with opposite optical purities in a fully reproducible way (54 $\pm 1 \%$ e.e., Table S.1).

In order to implement our concept, a scalemic mixture of enantiopure co-monomers has to promote the asymmetric 


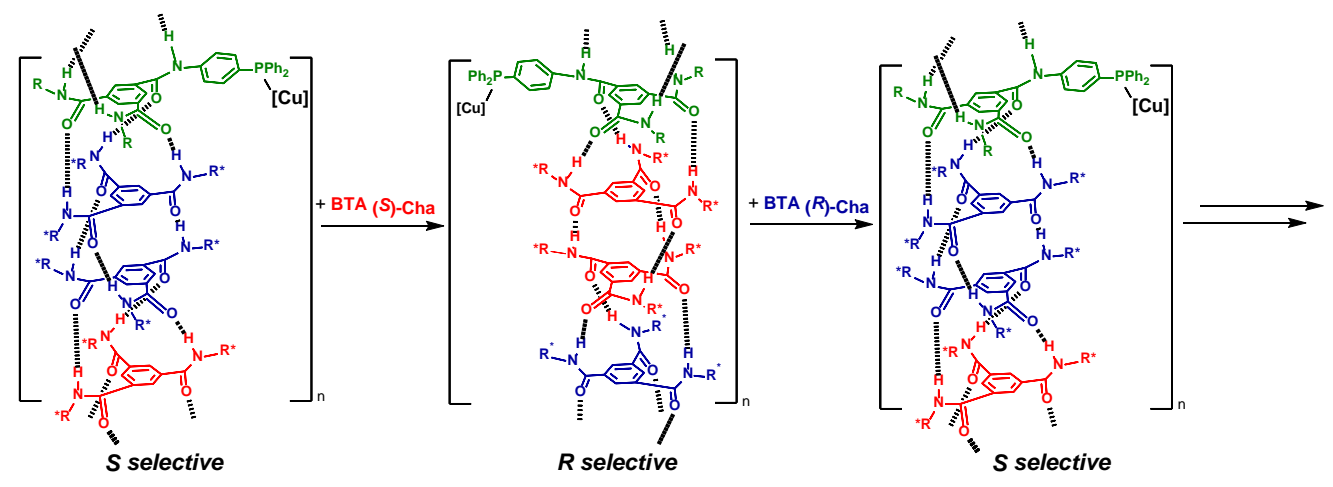

Scheme 1. Real-time control of the enantioselectivity of a supramolecular metal catalyst. The outcome of the catalytic reaction and the structure of the BTA assemblies were correlated according to various spectroscopic and scattering analyses. For the chemical structure of BTA Cha see Chart 1.

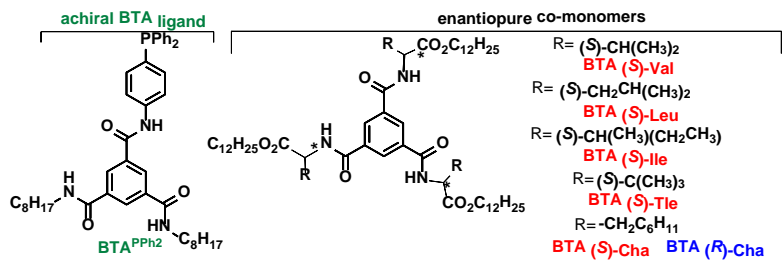

Chart 1. Chemical structures of BTA monomers screened in this study.

Table 1: Catalytic screening of BTA monomers for the copper-catalysed hydrosilylation of NPnone. ${ }^{[a]}$

\begin{tabular}{|c|c|c|}
\hline \multirow{3}{*}{$\begin{array}{l}0.29 \mathrm{M} \\
\text { Entry }\end{array}$} & \multicolumn{2}{|c|}{$\begin{array}{l}\text { 1. } \mathrm{Cu}(\mathrm{OAC}))_{2} \cdot \mathrm{H}_{2} \mathrm{O}(3 \mathrm{~mol} \%) \\
\mathrm{BTA}^{\mathrm{PPh} 2}(6 \mathrm{~mol} \%) \text {, co-monomer }(6.6 \mathrm{~mol} \%) \\
\mathrm{PhSiH}_{3}(0.29 \mathrm{M}) \\
\text { toluene, } 20^{\circ} \mathrm{C}, 30 \mathrm{~min}\end{array}$} \\
\hline & 2. $\mathrm{HCl}_{(10 \%)}$ & \\
\hline & co-monomer & e.e. $(\%)$ \\
\hline 1 & BTA (S)-Tle & $+47(R)$ \\
\hline 2 & BTA (S)-Val & $+48(R)$ \\
\hline 3 & BTA (S)-Leu & $+53(R)$ \\
\hline 4 & BTA (S)-Ile & $+53(R)$ \\
\hline 5 & BTA (S)-Cha & +54 (R) \\
\hline 6 & BTA $(R)$-Cha & $-54 \pm 1(S)^{[b]}$ \\
\hline
\end{tabular}

[a] Conversion>99\%. [b] Based on repeatability tests (Table S.1).

reaction with a level of selectivity similar to that of the enantiopure monomer. We thus probed the selectivity obtained by mixing BTA $^{\mathrm{PPh} 2}$ and a scalemic mixture of BTA Cha (25\% e.e. in favour of BTA $(\boldsymbol{R})$-Cha) for the hydrosilylation of NPnone. Whatever the conditions probed (temperature, molar ratio of BTA Cha over BTA ${ }^{\text {PPh2 }}$ ), the enantioselectivity of the reaction remains higher than expected when considering only the optical purity of the engaged scalemic mixture (Table S.2). These chirality amplification effects are particularly strong at $20^{\circ} \mathrm{C}$ since a $25 \%$ e.e. scalemic mixture provides the product with $85 \%$ of the optimal selectivity. We further assessed the selectivity obtained for various scalemic mixtures of BTA Cha at $0^{\circ} \mathrm{C}$ (Figure 1a, blue curve). The plot displays a sigmoidal shape with a plateau, corresponding to the optimal selectivity, reached at a value of ca. $50 \%$ e.e. of BTA Cha. The chirality amplification is slightly decreased at this temperature since $33 \%$ e.e. scalemic mixtures are required to get $88 \%$ of the optimal selectivity. This reduction of the chirality amplification effect at lower temperatures has been observed previously in majority-rule experiments conducted with alkyl BTAs (see further detail in Table S.2). ${ }^{[16]}$ The curve is symmetrical (inversion point at $\mathrm{x}=0$ ): it demonstrates that the enantiomeric state of the catalyst can be inverted by simply changing the nature of the major enantiomer in the co-assemblies (vide infra). To further ascertain the origin of this chirality amplification effect, we precisely investigated the nature of the assemblies. When studied individually, BTA ${ }^{\mathrm{PPh} 2}$ (Figure S.1) and BTA (S)-Cha (Figure S.2) assemble into stacks $^{[11]}$ and dimers ${ }^{[17]}$ respectively at $\mathrm{mM}$ concentration in toluene, in agreement with our previous results. The formation of co-assemblies between BTA ${ }^{\text {PPh2 }}$ and BTA (S)-Cha ([BTA (S)Cha $] /\left[\mathbf{B T A}^{\mathrm{PPh}}\right]=1.1$ ) in toluene is confirmed by FT-IR (Figures S.3 and S.4) and Small Angle Neutron Scattering analyses (SANS, Figure S.5). According to a quantitative analysis of such data, ${ }^{[11 \mathrm{~b}]}$ the amount of BTA (S)-Cha incorporated into the stacks is $~ 50 \%$ meaning that ca. $35 \%$ of the BTA monomers present in the co-assemblies are enantiopure. The chiroptical properties of the co-assemblies were then assessed by Circular Dichroism (CD, Figure S.6). ${ }^{[18]}$ All mixtures of BTA Cha and BTA ${ }^{\text {PPh2 }}$ show a Cotton effect centred at $\lambda=310 \mathrm{~nm}$, the sign of which depends on the nature of the major enantiomer present in the coassemblies (Figure S.7). As only BTA ${ }^{\text {PPh2 }}$ absorbs in this region, the presence of this induced $C D$ signal| ${ }^{[19]}$ confirms that the phosphine groups of the ligand are located in the chiral environment provided by the co-assemblies and that the direction of the induced chirality is controlled by the co-monomer. As expected, the plot of the net helicity as a function of the e.e. of BTA Cha for various scalemic mixtures shows that chirality amplification effects govern the formation of single-handed helices (Figure 1a, black curve). Indeed, 33\% e.e. scalemic mixtures form homochiral assemblies. ${ }^{[20]}$ This demonstrates that the chirality amplification effect observed in the catalytic experiments mentioned above stems from the chirally-amplified nature of the helical scaffold of the catalyst. Based on the sign of the CD signal in the $200-270 \mathrm{~nm}$ region (Figure S.8), ${ }^{[13 \mathrm{~b}]}$ the outcome of the catalytic reaction can be correlated to the structure of the co-assemblies: scalemic mixtures biased in favour of BTA $(\boldsymbol{R})$-Cha form left-handed helices supporting $\mathrm{Cu}$ catalytic centres which in turn provide the $(S)$ enantiomer of the hydrosilylation product (see a schematic representation in Scheme 1).

a) 

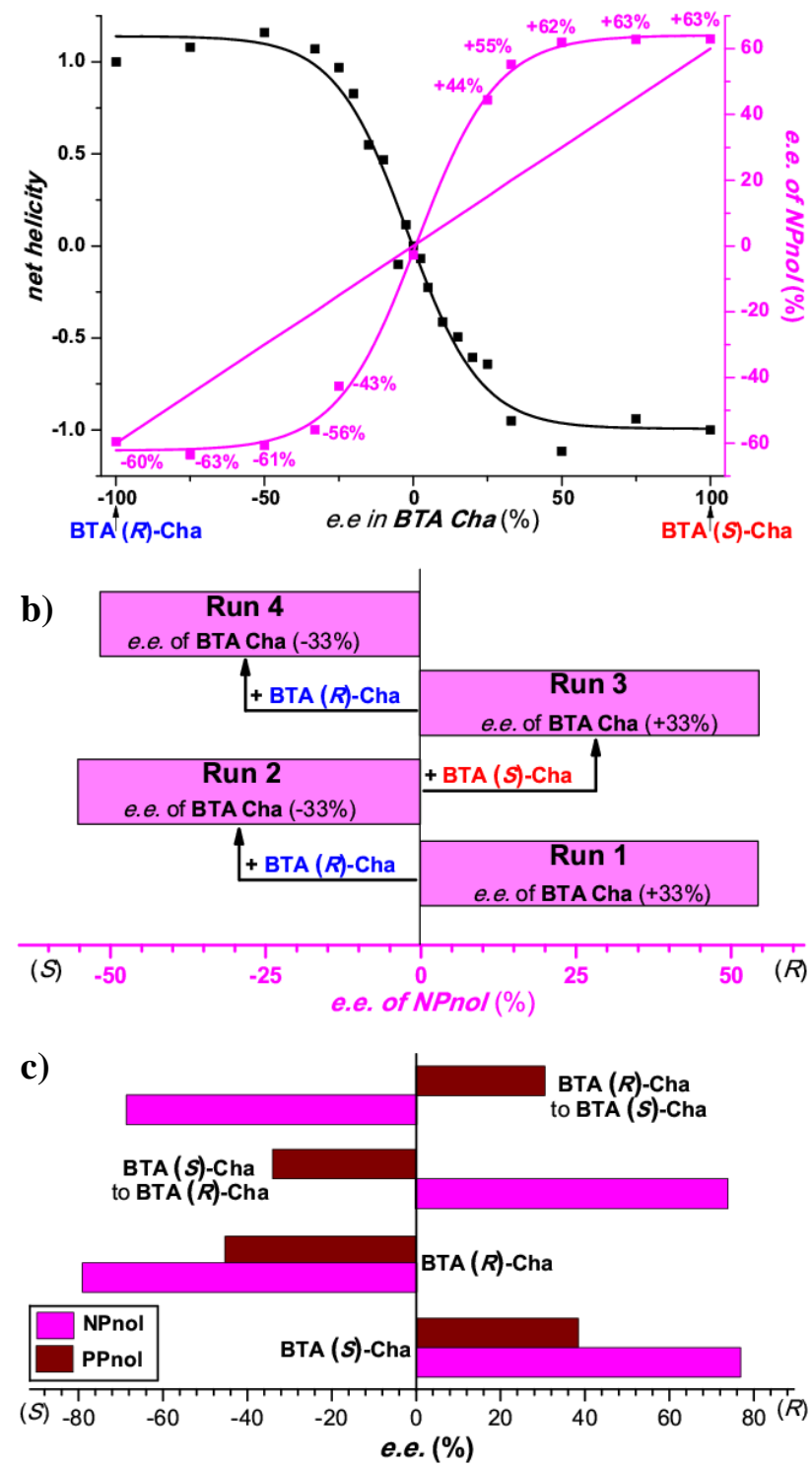

Figure 1. a) Enantiomeric excess of 1-(4-nitrophenyl)ethanol (NPnol) and net helicity versus BTA Cha enantiomeric excess. See Table S.2 for reaction conditions. The blue line represents the selectivity that would be obtained in absence of chirality amplification. The net helicity for the various coassemblies was measured by $C D$ spectroscopy by dividing the ellipticity $(\lambda=305 \mathrm{~nm})$ of each mixture by the ellipticity of the mixture containing enantiopure BTA Cha (Figure S.7). The curves are guides to the eye. b) Copper-catalysed hydrosilylation of NPnone with sequential additions of substrate and $\mathrm{PhSiH}_{3}$. Amount of BTA Cha added during the reaction: BTA (R)-Cha (13.0 mol\%, run 2), BTA (S)-Cha (26.0 mol\%, run 3), BTA (R)-Cha (52.0 mol\%, run 4). See Table S.3 for more experimental details. c) Coppercatalysed hydrosilylation of a 1:1 mixture of NPnone and PPnone. For the selectivity-inverting experiments, 20.0 mol\% of BTA Cha was added during the reaction. See Table S.5 for more experimental details.

To demonstrate the dynamic nature of the catalytic system, we first envisaged to switch its selectivity in situ in a procedure involving sequential additions of $\mathrm{NPnone}$ and $\mathrm{PhSiH}_{3}$ (Table S.3). The reaction was started with a scalemic mixture biased in favour of BTA (S)-Cha (+33\% e.e., run 1). After 15 minutes, complete conversion of the substrate was achieved leading to $(R)$-1-(4-nitro)phenylethanol with 53\% e.e. Then BTA $(\boldsymbol{R})$-Cha was added in order to invert the enantiomer bias in the mixture (-33\% e.e. of BTA Cha, run 2) and thus the handedness of the co-assemblies. The same protocol was reproduced in order to get 4 successive runs corresponding to three switches of the selectivity. The enantioselectivity for each run was deduced from the cumulative selectivity measured by chiral Gas
Chromatography (GC). The full inversion of the selectivity observed for each consecutive run (Figure 1b) confirms that the enantiomeric state of the catalyst can be completely switched in situ. In addition, thanks to the chirally-amplified helical scaffold (vide supra), the selectivity of the run (54\% e.e. on average) is close to the optimal selectivity (63\% e.e.) achievable under these experimental conditions. In comparison, $21 \%$ e.e. would have been obtained in absence of chirality amplification (Figure S.10). We then measured the time required for the stereochemical switch by adding the BTA co-monomer (switch trigger) and $\mathrm{PhSiH}_{3}$ (reaction trigger) at different time intervals. According to the result presented in Table S.4, full enantioinversion is achieved in ca. 5 seconds. The reaction time of NPnone is of the same order and thus the chirality switch cannot be fully accomplished during the conversion of this substrate. In contrast, the reaction rate of 1-(4-biphenylyl)ethanone (PPnone) is lower which allows the enantioinversion process to be performed during its transformation with no negative impact on the obtained selectivity (Scheme S.1).

The previous experiments prompted us to probe the possibility of inverting the selectivity of the catalyst during the hydrosilylation of a 1:1 mixture of NPnone and PPnone. We performed two experiments with enantiopure co-monomers (BTA (S)-Cha and BTA (R)-Cha) and two selectivity-inverting experiments starting with a scalemic mixture of enantiopure comonomers $(+60 \%$ e.e. $\rightarrow-60 \%$ e.e. and $-60 \%$ e.e. $\rightarrow+60 \%$ e.e., Table S.5). As expected, 1-(4-nitrophenyl)ethanol (NPnol) and 1(4-biphenylyl)ethanol (PPnol) were obtained with the same preferred configuration, i.e. predominantly $(R)$ or $(S)$, when the reaction was conducted with a single enantiomer of the BTA comonomer (Figure 1c). More precisely, the experiment performed in the presence of BTA $(S)$-Cha (respectively BTA $(R)$-Cha) provided the alcohols with optimal selectivities: $+77 \% /+38 \%$ e.e. (respectively $-79 \% /-45 \%$ e.e.) for NPnol and PPnol. In contrast, the alcohols were obtained with an opposite preferred configuration, e.g. one is predominantly $(R)$ whilst the other is predominantly $(S)$, when the enantiomer in excess in the coassemblies was changed during the course of the catalytic reaction. The selectivities obtained for these experiments $+74 \% /-34 \%$ e.e. or $-69 \% /+30 \%$ e.e. (NPnol/PPnol) compared well with those obtained with a single co-monomer (Figure 1c). Any combination of the enantiomers is thus obtained in a onepot procedure without significant dwindling of the catalyst selectivity. ${ }^{[7 g, 9]}$

We have exploited the chirality amplification properties of supramolecular polymer helices to control in situ the enantioselectivity displayed by phosphine copper catalytic centres located at their periphery. Switching the enantiomeric state of a catalyst in between sequential transformations could provide access to any diastereomer in cascade stereoselective reactions without purification of the reaction intermediate. ${ }^{[15]}$ Also, a fast stereochemical switch is key for a precise stereocontrol of polymerization reactions. ${ }^{[5]}$ The selectivity of the present catalytic system can be inverted both in between different reactions and in real time during the reaction. Improving the catalytic efficiency should be possible by combining the present concept with the recent advances achieved in tuning the composition, the structure, the stability and the stimuli-responsiveness of supramolecular polymers and assemblies. ${ }^{[21]}$

\section{Acknowledgements}

This work was supported by the French Agence Nationale de la Recherche (project ANR-13-BS07-0021 SupraCatal) and by the 
China Scholarship Council (CSC, PhD grant of Y.L.). Jacques Jestin (LLB, Saclay) is acknowledged for assistance with SANS experiment and Nicolas Vanthuyne (iSm2, Marseille) for chiral HPLC analyses.

Keywords: supramolecular catalysis • selectivity-switchable catalyst $\bullet$ functional polymer $\bullet$ dynamic catalyst $\bullet$ chirality amplification

[1] a) N. Kumagai, M. Shibasaki, Catal. Sci. Technol. 2013, 3, 41-57; b) V. Blanco, D. A. Leigh, V. Marcos, Chem. Soc. Rev. 2015, 44, 5341-5370; c) M. Vlatković, B. S. L. Collins, B. L. Feringa, Chem. Eur. J. 2016, 22, 17080-17111.

[2] X. K. Wang, A. Thevenon, J. L. Brosmer, I. S. Yu, S. I. Khan, P. Mehrkhodavandi, P. L. Diaconescu, J. Am. Chem. Soc. 2014, 136, 11264-11267.

[3] a) A. Nojiri, N. Kumagai, M. Shibasaki, J. Am. Chem. Soc. 2009, 131, 3779-3784; b) X. Tian, C. Cassani, Y. K. Liu, A. Moran, A. Urakawa, P. Galzerano, E. Arceo, P. Melchiorre, J. Am. Chem. Soc. 2011, 133, 17934-17941.

[4] a) L. L. Lin, X. M. Feng, Chem. Eur. J. 2017, 23, 6464-6482; b) S. Krautwald, E. M. Carreira, J. Am. Chem. Soc. 2017, 139, 5627-5639.

[5] a) Coates, G. W.; Waymouth, R. M. Science 1995, 267, 217. b) C. M. Thomas, Chem. Soc. Rev. 2010, 39, 165-173.

[6] a) J. Escorihuela, M. I. Burguete, S. V. Luis, Chem. Soc. Rev. 2013, 42, 5595-5617; b) G. Romanazzi, L. Degennaro, P. Mastrorilli, R. Luisi, ACS Catal. 2017, 7, 4100-4114.

[7] a) J. B. Wang, B. L. Feringa, Science 2011, 331, 1429-1432; b) M. Vlatković, L. Bernardi, E. Otten, B. L. Feringa, Chem. Commun. 2014, 50, 7773-7775; c) C.-T. Chen, C.-C. Tsai, P.-K. Tsou, G.-T. Huang, C.H. Yu, Chem. Sci. 2016, 8, 524-529; d) S. Mortezaei, N. R. Catarineu, J. W. Canary, J. Am. Chem. Soc. 2012, 134, 8054-8057; e) S. Mortezaei, N. R. Catarineu, X. Y. Duan, C. H. Hu, J. W. Canary, Chem. Sci. 2015, 6, 5904-5912; f) B. A. F. Le Bailly, L. Byrne, J. Clayden, Angew. Chem. Int. Ed. 2016, 55, 2132-2136; Angew. Chem. 2016, 128, 2172-2176; g) D. P. Zhao, T. M. Neubauer, B. L. Feringa, Nat. Commun. 2015, 6; h) T. Yamamoto, T. Adachi, M. Suginome, ACS Macro Lett. 2013, 2, 790-793; i) Y. Nagata, T. Nishikawa, M. Suginome, J. Am. Chem. Soc. 2015, 137, 4070-4073; j) Y. Nagata, T. Nishikawa, M. Suginome, ACS Macro Lett. 2016, 5, 519-522; k) Y.-Z. Ke, Y. Nagata, T. Yamada, M. Suginome, Angew. Chem. Int. Ed. 2015, 54, 9333-9337; Angew. Chem. 2015, 127, 9465-9469.

[8] For solvent-controlled inversion of the selectivity of an organocatalyst involved in two successive reactions see: Y. Sohtome, T. Yamaguchi, S. Tanaka, K. Nagasawa, Org. Biomol. Chem. 2013, 11, 2780-2786

[9] For a previous example of reversal of enantioselectivity during the course of an organocatalytic reaction see: S. Mortezaei, N. R. Catarineu, J. W. Canary, Tetrahedron Lett. 2016, 57, 459-462.

[10] D. Sud, T. B. Norsten, N. R. Branda, Angew. Chem. Int. Ed. 2005, 44, 2019-2021; Angew. Chem. 2005, 117, 2055-2057.

[11] a) M. Raynal, F. Portier, P. W. N. M. van Leeuwen, L. Bouteiller, J. Am. Chem. Soc. 2013, 135, 17687-17690; b) A. Desmarchelier, X. Caumes, M. Raynal, A. Vidal-Ferran, P. W. N. M. van Leeuwen, L. Bouteiller, J. Am. Chem. Soc. 2016, 138, 4908-4916.

[12] a) A. R. A. Palmans, E. W. Meijer, Angew. Chem. Int. Ed. 2007, 46, 8948-8968; b) E. Yashima, N. Ousaka, D. Taura, K. Shimomura, T. Ikai, K. Maeda, Chem. Rev. 2016, 116, 13752-13990. c) J. Jiang, G. Ouyang, L. Zhang, M. Liu, Chem. Eur. J. 2017, 23, 9439.

[13] a) S. Cantekin, T. F. A. de Greef, A. R. A. Palmans, Chem. Soc. Rev. 2012, 41, 6125-6137; b) Y. According to the assignment made by Meijer and co-workers: M. M. J. Smulders, T. Buffeteau, D. Cavagnat, M. Wolffs, A. P. H. J. Schenning, E. W. Meijer, Chirality 2008, 20, 10161022.

[14] A. J. Jordan, G. Lalic, J. P. Sadighi, Chem. Rev. 2016, 116, 8318-8372.

[15] S.-L. Shi, Z. L. Wong, S. L. Buchwald, Nature 2016, 532, 353-356.

[16] M. M. J. Smulders, I. A. W. Filot, J. M. A. Leenders, P. Van der Schoot, A. R. A. Palmans, A. P. H. J. Schenning, E. W. Meijer, J. Am. Chem. Soc. 2010, 132, 611-619.

[17] a) A. Desmarchelier, M. Raynal, P. Brocorens, N. Vanthuyne, L. Bouteiller, Chem. Commun. 2015, 51, 7397-7400; b) X. Caumes, A.
Baldi, G. Gontard, P. Brocorens, R. Lazzaroni, N. Vanthuyne, C. Troufflard, M. Raynal, L. Bouteiller, Chem. Commun. 2016, 52, 1336913372; c) A. Desmarchelier et al. Soft Matter 2016, 12, 7824-7838.

[18] The CD experiments were conducted in methylcyclohexane ([BTA (Cha)/[BTA $\left.{ }^{\mathrm{PPh} 2}\right]=2.2,2.0 \mathrm{mM}$ ).

[19] S. Allenmark, Chirality 2003, 15, 409-422.

[20] The same result is obtained when the CD spectra are processed in order to remove the contribution of the dimers to the overall CD signal (Figures S.8 and S.9). .

[21] a) J. Kang, D. Miyajima, T. Mori, Y. Inoue, Y. Itoh, T. Aida, Science 2015, 347, 646-651; b) P. Besenius, J. Polym. Sci. Pol. Chem. 2017, 55, 34-78; c) J. R. Nitschke, Nature 2009, 462, 736-738; d) R. A. R. Hunt, S. Otto, Chem. Commun. 2011, 47, 847-858. 
Change it easy! A first step towards selecting the configuration of consecutively formed stereogenic centres in cascade or polymerization reactions has now been achieved by controlling the enantioselectivity of a metal catalyst in real time. The strategy relies on the complete and fast stereochemical switch of the handedness of the dynamic helices supporting the catalytic centres.

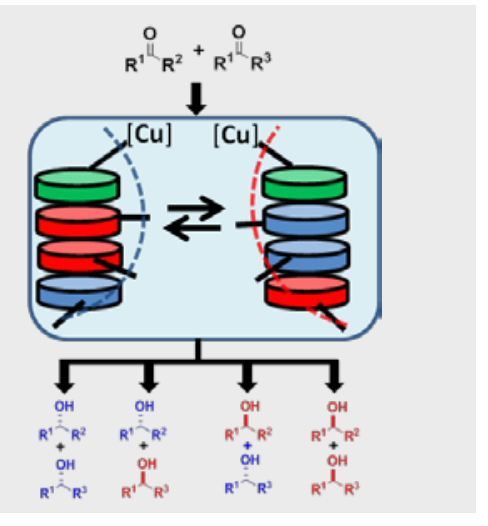

Dr. Jeremy M. Zimbron, Dr. Xavier Caumes, Yan Li, Dr. Christophe M. Thomas, Dr. Matthieu Raynal, ${ }^{\star} D r$. Laurent Bouteiller

Real-time control of the enantioselectivity of a supramolecular catalyst allows selecting the configuration of consecutively formed stereogenic centres 


\section{Supporting Information}

Catalytic experiments: chirality induction and amplification [Tables S.1 and S.2] ................. 2 Characterization of the Cu supramolecular catalyst by means of various spectroscopic and

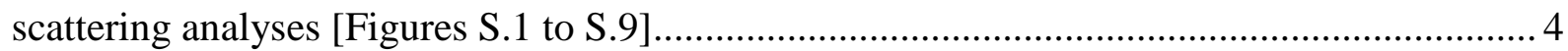

Selectivity-switching experiments [Tables S.3 to S.5, Scheme S.1, Figure S.10].................. 13

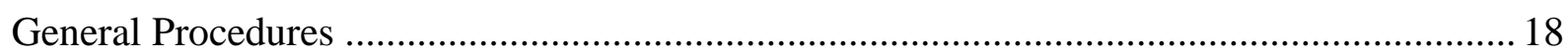

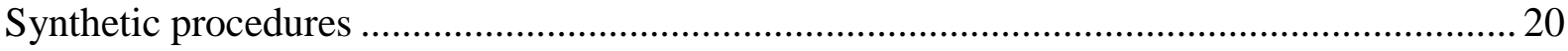

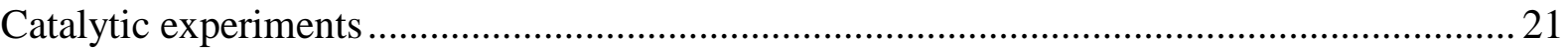

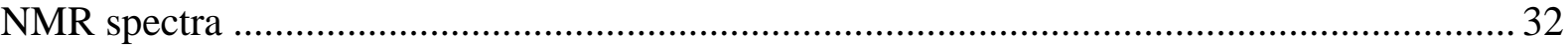

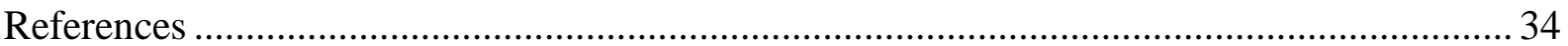




\section{Supplementary Tables. Catalytic experiments: chirality induction and}

\section{amplification [Tables S.1 and S.2]}

Table S.1 Repeatability of the catalytic experiments for the hydrosilylation of 1-(4nitrophenyl)ethanone. ${ }^{\text {[a] }}$
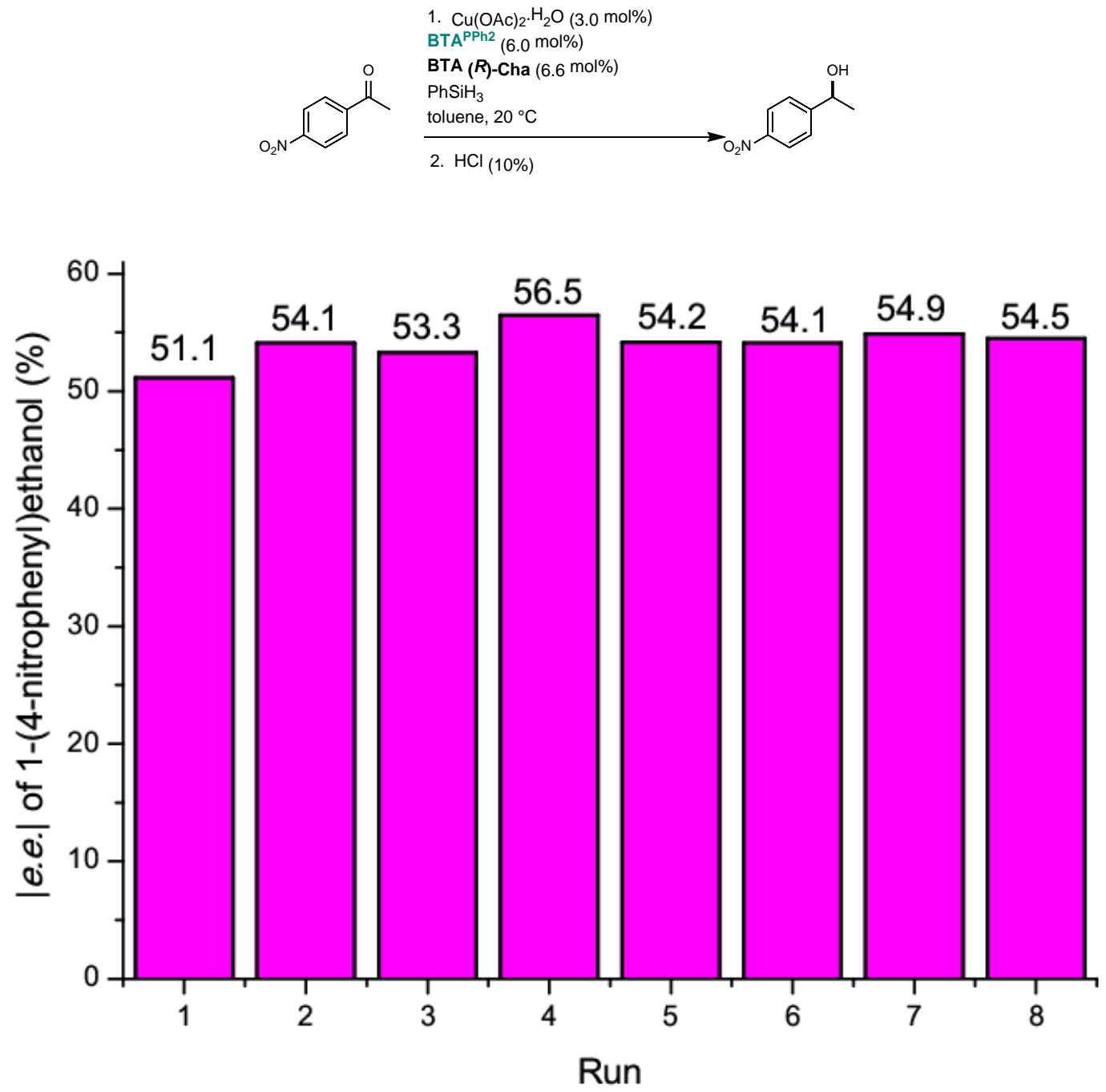

[a] The above table summarizes 8 batches of reactions that have been repeated in the same conditions namely: 1-(4nitrophenyl)ethanone (0.29 M), Cu(OAc) ${ }_{2} \cdot \mathrm{H}_{2} \mathrm{O}$ (3.0 mol\%), BTA ${ }^{\mathbf{P P h} 2}(6.0 \mathrm{~mol} \%, 16.9 \mathrm{mM})$, BTA (R)-Cha (6.6 mol\%, 18.6 $\mathrm{mM}), \mathrm{PhSiH}_{3}(0.29 \mathrm{M})$, toluene, $20^{\circ} \mathrm{C}, 30 \mathrm{~min}$. Conversion $>99 \%$ was obtained for all runs as determined by GC and ${ }^{1} \mathrm{H}$ NMR analyses. Based on this repeatability assessment, a mean e.e. value of $54.1 \%$ is determined over the 8 runs. The standard deviation is $\mathrm{s}=1.4$ and the variance is $\mathrm{s}^{2}=2.0$. Accordingly, an error bar of $\pm 1 / 2$ variance $( \pm 1 \%$ e.e.) was set to the e.e. values obtained with mixtures of BTA ${ }^{\text {PPh2 }}$ and BTA (R)-Cha (Table 1). 
Table S.2 Hydrosilylation of 1-(4-nitrophenyl)ethanone with a scalemic mixture of enantiopure BTA Cha co-monomers $(25 \% \text { e.e. })^{[a]}$

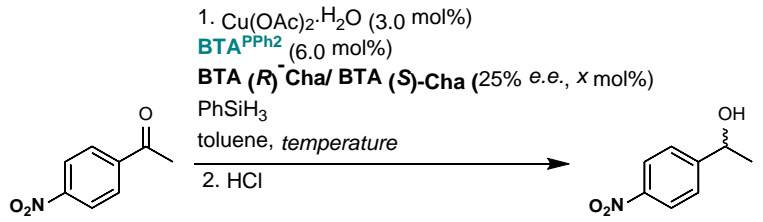

\begin{tabular}{ccccccc} 
Entry & $\mathrm{T}\left({ }^{\circ} \mathrm{C}\right)$ & $\begin{array}{c}\text { BTA (R)-Cha } \\
(\mathrm{mol} \%)\end{array}$ & $\begin{array}{c}\text { BTA (S)-Cha } \\
(\mathrm{mol} \%)\end{array}$ & $\begin{array}{c}\text { expected } \\
\text { unamplified } \\
\text { e.e. } \\
(\%)^{[\mathrm{b}]}\end{array}$ & $\begin{array}{c}\text { obtained } e . e . ~ \\
(\%)\end{array}$ & $R_{a m p l}{ }^{[\mathrm{c}]}$ \\
\hline 1 & $\mathbf{2 0}$ & 6.6 & 0 & - & -54 & - \\
2 & $\mathbf{2 0}$ & 4.1 & 2.5 & -13.5 & -39 & 2.86 \\
3 & $\mathbf{2 0}$ & 13.2 & 0 & - & -54 & - \\
4 & $\mathbf{2 0}$ & 8.2 & 5.0 & -13.5 & -45 & 3.33 \\
\hline 5 & $\mathbf{0}$ & 6.6 & 0 & - & -63 & - \\
6 & $\mathbf{0}$ & 4.1 & 2.5 & -15.8 & -27 & 1.72 \\
7 & $\mathbf{0}$ & 13.2 & 0 & - & -63 & - \\
8 & $\mathbf{0}$ & 8.2 & 5.0 & -15.8 & -45 & 2.87 \\
\hline 9 & $-\mathbf{2 5}$ & 6.6 & 0 & - & -78 & - \\
10 & $-\mathbf{2 5}$ & 4.1 & 2.5 & -19.5 & -29 & 1.47 \\
11 & $-\mathbf{2 5}$ & 13.2 & 0 & - & -78 & - \\
12 & $-\mathbf{2 5}$ & 8.2 & 5.0 & -19.5 & -34 & 1.72 \\
\hline
\end{tabular}

[a] Reaction conditions: 1-(4-nitrophenyl)ethanone (0.29 M), $\mathrm{Cu}(\mathrm{OAc})_{2} \cdot \mathrm{H}_{2} \mathrm{O}(3.0 \mathrm{~mol} \%), \mathbf{B T A}^{\text {PPh2 }}(6.0 \mathrm{~mol} \%, 16.9 \mathrm{mM})$, $25 \%$ e.e. scalemic mixture biased in favour of BTA $(\boldsymbol{R})$-Cha $\left(\mathrm{x}\right.$ mol\%), $\mathrm{PhSiH}_{3}(0.29 \mathrm{M})$, toluene. Conversion $>99 \%$ was obtained for all entries as determined by GC and ${ }^{1} \mathrm{H}$ NMR analyses.

[b] Expected e.e. in the absence of any chirality amplification effect, considering the optical purity of the engaged scalemic mixture of enantiopure BTA Cha.

[c] Majority-rule factor defined as Rampl= (obtained e.e.)/(expected e.e. in absence of chirality amplification). $R$ ampl=1.0 means no chirality amplification and the higher $R_{\text {ampl }}$ the higher the chirality amplification effect.

Conditions highlighted in orange have been selected for probing the chirality amplification effect displayed by the catalytic assemblies (Fig. 1a). Reaction conditions: 1-(4-nitrophenyl)ethanone (0.29 M), $\mathrm{Cu}(\mathrm{OAc})_{2} \cdot \mathrm{H}_{2} \mathrm{O}(3.0 \mathrm{~mol} \%), \mathbf{B T A}^{\mathbf{P P h} 2}(6.0$ mol\%, $16.9 \mathrm{mM}$ ), BTA (R)-Cha/BTA (S)-Cha (x \% e.e., $13.2 \mathrm{~mol} \%), \mathrm{PhSiH}_{3}(0.29 \mathrm{M})$, toluene, $0^{\circ} \mathrm{C}$. Conversion $>99 \%$ was obtained in all cases as determined by GC and ${ }^{1} \mathrm{H}$ NMR analyses. 
Supplementary Tables and Figures: Characterization of the $\mathrm{Cu}$ supramolecular catalyst by means of various spectroscopic and scattering analyses [Figures S.1 to S.9]

Postulated active copper hydride species (made by reacting $\mathbf{B T A} \mathbf{A}^{\mathbf{P P h} 2}, \mathrm{Cu}(\mathrm{OAc})_{2} \cdot \mathrm{H}_{2} \mathrm{O}$ and $\mathrm{PhSiH}_{3}$ ) are poorly stable under our experimental conditions in the absence of substrate or product. Accordingly, in the following, we will focus on the characterization of the co-assemblies formed by mixing: i) $\mathbf{B T A}^{\mathbf{P P h} 2}$ and $\mathbf{B T A}(\boldsymbol{R})$-Cha, and ii) $\mathbf{B T A}^{\mathbf{P P h} 2}$ coordinated to Cu (BTA $\left.^{\text {PPh2}} / \mathrm{Cu}(\mathrm{OAc})_{2} \cdot \mathrm{H}_{2} \mathrm{O}=2.0\right)$ and BTA (R)-Cha. 


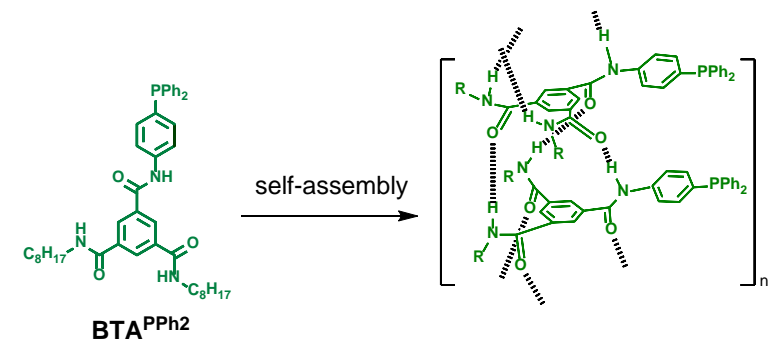

a)

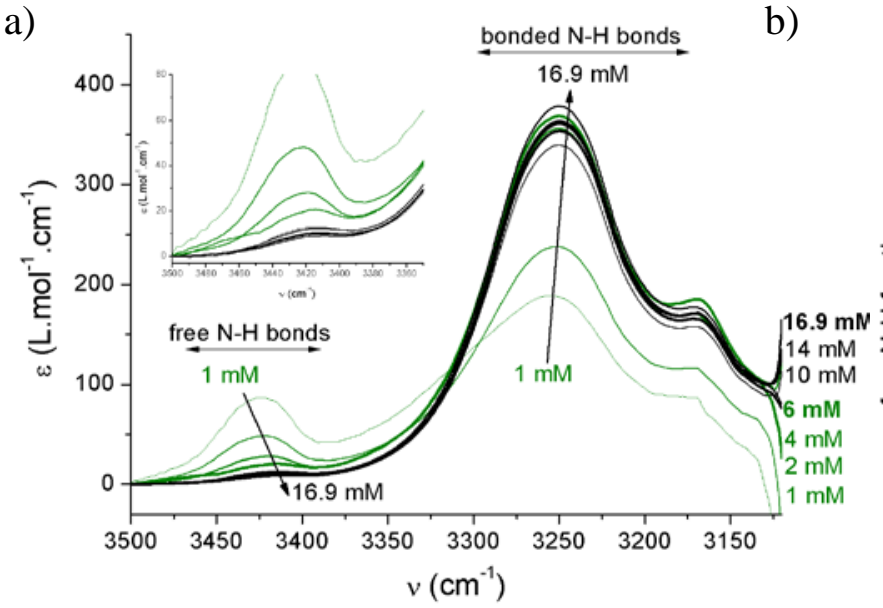

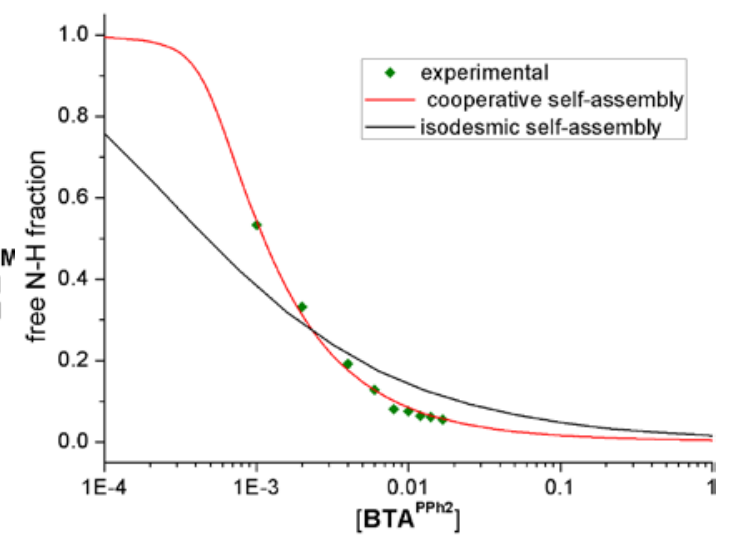

c)

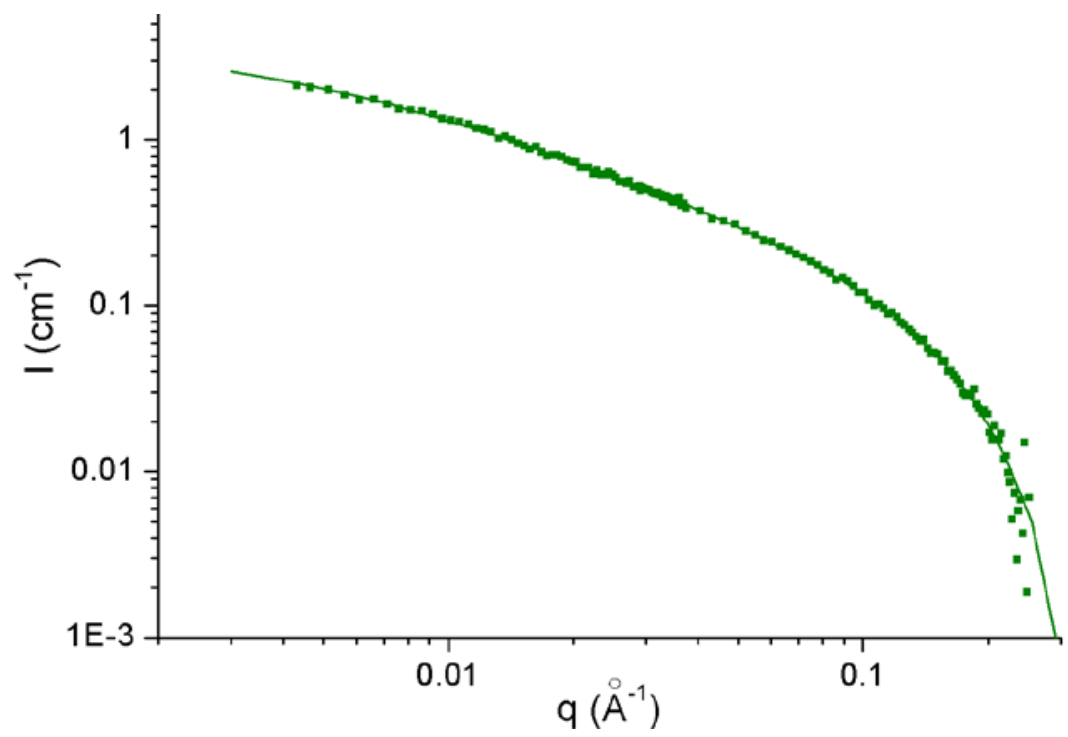

Figure S.1 Characterization of the homo-assemblies formed by $\mathbf{B T A}^{\text {PPh2 }}$. (a) FT-IR analyses of BTA $^{\text {PPh2 }}$ at various concentrations in toluene $\left(20^{\circ} \mathrm{C}\right)$. Zoom on the N-H region. (b) Plot of the free N-

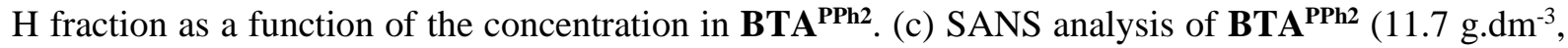
$16.9 \mathrm{mM})$ in toluene- $\mathrm{d}_{8}\left(20^{\circ} \mathrm{C}\right)$.

The absorption band at $v=3235 \mathrm{~cm}^{-1}$ (a) is diagnostic of the bonded $\mathrm{N}-\mathrm{H}$ present in stacks whilst the absorption band at $v=3430 \mathrm{~cm}^{-1}$ is diagnostic of free N-H (belonging either to monomers or to BTA molecules located at the chain-ends of the assemblies). The fraction of free $\mathrm{N}-\mathrm{H}$ can be deduced from these FT-IR data by a linear regression of the plot of $\left(\left[\right.\right.$ BTA $\left.\left.^{\text {PPh2 }}\right] \times 1\right) / \mathrm{A}_{b}{ }^{\mathrm{N}-\mathrm{H}}$ versus $\mathrm{A}_{\mathrm{f}}^{\mathrm{N}-\mathrm{H} / \mathrm{A}_{b}}{ }^{\mathrm{N}-\mathrm{H}}$ with $\left[\right.$ BTA $\left.^{\mathbf{P P h} 2}\right]=$ total concentration in $\mathbf{B T A}^{\mathbf{P P h} 2}, \mathrm{l}=$ cell pathlength, $\mathrm{A}_{\mathrm{b}}{ }^{\mathrm{N}-\mathrm{H}}=$ maximum of the absorption band for bonded $\mathrm{N}-\mathrm{H}, \mathrm{Af}_{\mathrm{f}}^{\mathrm{N}-\mathrm{H}}=$ maximum of the absorption band for free $\mathrm{N}-\mathrm{H}$. It provides the following value for the molar extinction coefficients: $\varepsilon_{\mathrm{b}} \mathrm{N-H}=390 \mathrm{~L} \cdot \mathrm{mol}^{-1} \cdot \mathrm{cm}^{-1}$ and $\varepsilon_{\mathrm{f}} \mathrm{N-H}=158 \mathrm{~L}_{\mathrm{mol}}{ }^{-1} \cdot \mathrm{cm}^{-1}$. The data in (b) can be perfectly fitted by a cooperative model for self-assembly ${ }^{[1]}\left(\mathrm{K}_{2} / \mathrm{K}\right.$ model) but not by an isodesmic model. ${ }^{[2]}$ The fit gives the following values: $\mathrm{K}_{2}=35 \mathrm{M}^{-1}, \mathrm{~K}=1794 \mathrm{M}^{-1}, \mathrm{~K} / \mathrm{K}_{2}=51$ ( $\mathrm{DPn}=18$ and $\mathrm{DPw}=75$ for [BTA ${ }^{\mathrm{PPh}}$ ] $\left.=16.9 \mathrm{mM}\right)$. SANS analysis of BTA $^{\text {PPh2 }}$ (c) is fitted with the form factor for long and rigid rods with a circular cross-section and a uniform scattering length density (with the DANSE software SasView). The fit yields a radius of $11.5 \AA$ and a length of $204 \AA$ for the stacks formed by BTA $^{\text {PPh2 }}$. 

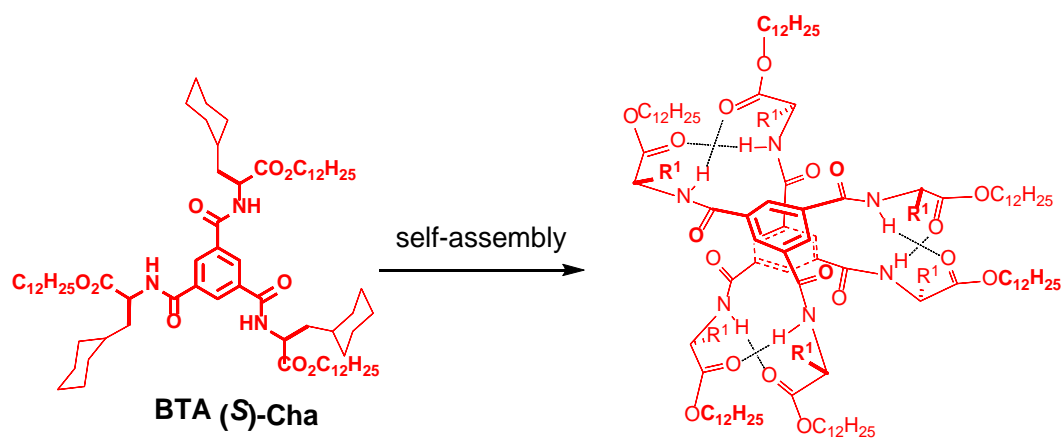

a)

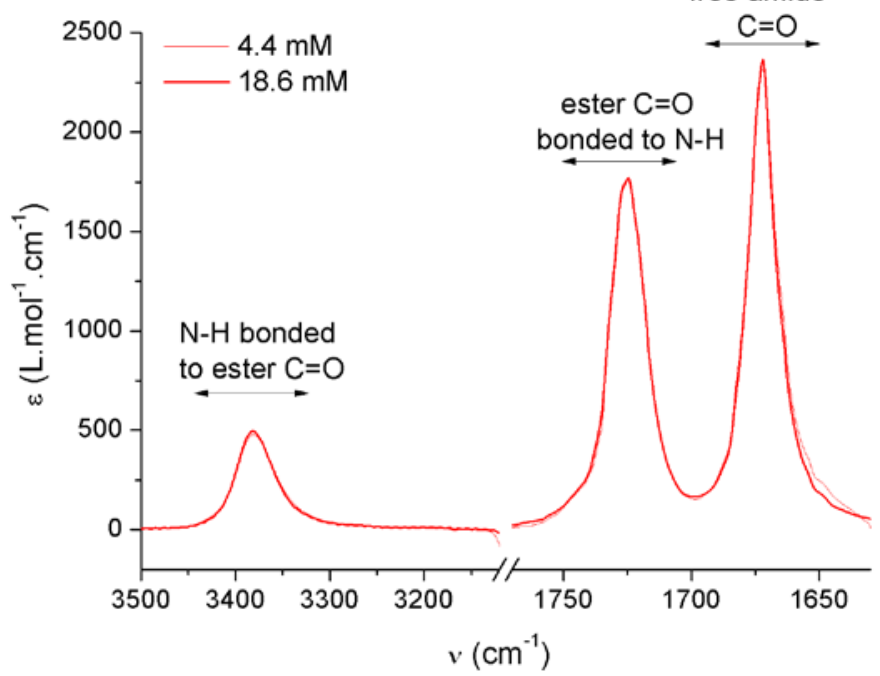

b)

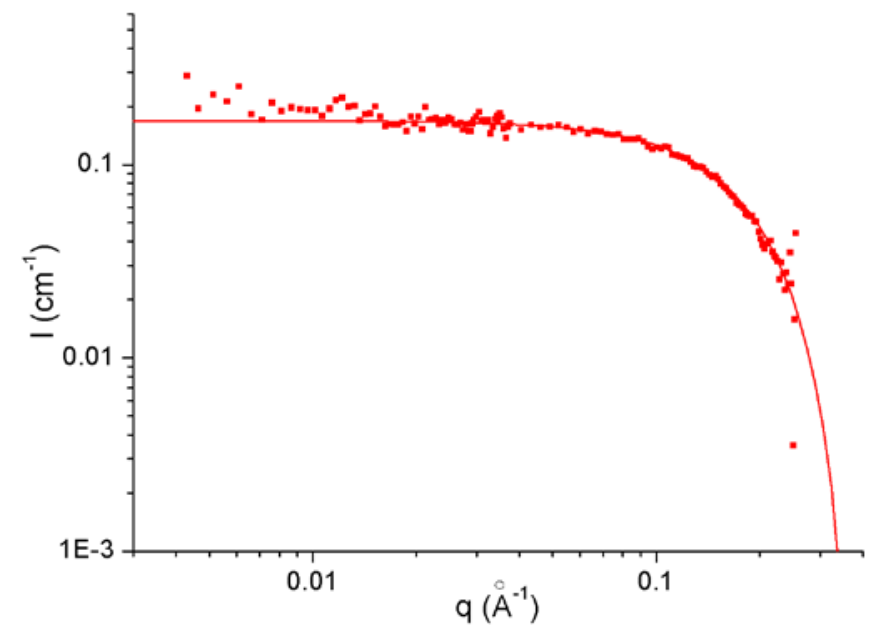

Figure S.2 Characterization of the homo-assemblies formed by BTA (S)-Cha. (a) FT-IR analyses of BTA Cha at $4.4 \mathrm{mM}$ and $18.6 \mathrm{mM}$ in toluene $\left(20^{\circ} \mathrm{C}\right)$. Zoom on the $\mathrm{N}-\mathrm{H}$ and $\mathrm{C}=\mathrm{O}$ region. (b) SANS analysis of BTA (S)-Cha (21.9 g.dm $\left.{ }^{-3}, 18.6 \mathrm{mM}\right)$ in toluene- $\mathrm{d}_{8}\left(20^{\circ} \mathrm{C}\right)$.

The absorption band at $v=3381 \mathrm{~cm}^{-1}$ (a) corresponds to $\mathrm{N}-\mathrm{H}$ bonded to carbonyl ester functions and is diagnostic of the hydrogen-bonded network present in the ester-bonded dimers formed by ester BTAs. SANS analysis of BTA (S)-Cha (b) confirms the formation of small assemblies since the scattering curve can be fitted according to a form factor for spherical objects having 1.5 times the molar mass of the monomer (result of the fit: $r=12.0 \AA$ and $M=1750$ g.mol ${ }^{-1}$ ). More details on the structure and stability of the ester-bonded dimers formed by ester BTAs can be found in the literature. ${ }^{[3]}$ 
Characterization of the co-assemblies formed by $\mathrm{BTA}^{\mathrm{PPh}}$, coordinated or not to copper, and BTA (S)-Cha.
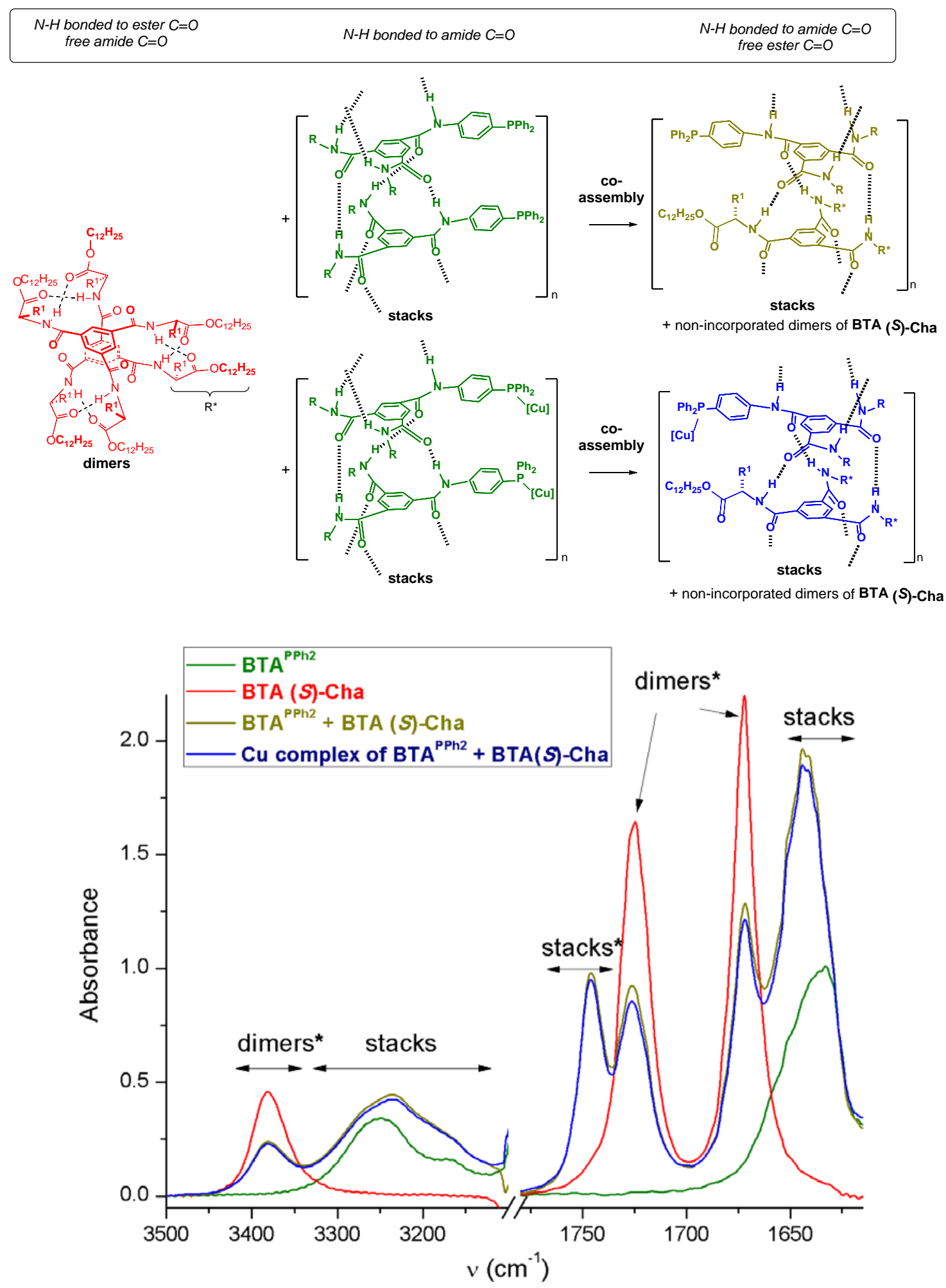

Figure S.3 FT-IR analyses of BTA ${ }^{\text {PPh2 }}(16.9 \mathrm{mM})$, of BTA $(\boldsymbol{S})$-Cha $(18.6 \mathrm{mM})$ and of the mixtures of BTA $^{\text {PPh2 }}(16.9 \mathrm{mM})$ and BTA $(\boldsymbol{S})$-Cha $(18.6 \mathrm{mM})$ with and without $\mathrm{Cu}$ coordinated to $\mathbf{B T A}^{\mathbf{P P h} 2}$ in toluene at $20^{\circ} \mathrm{C}$.

* These absorption bands belong exclusively to BTA (S)-Cha either in dimers or in stacks (co-assembly). 
Upon co-assembly, a fraction of BTA (S)-Cha molecules is incorporated into the stacks formed by $\mathbf{B T A}^{\text {PPh2 }}$ as indicated by: i) the decreased intensity of the absorption bands belonging to BTA $(\boldsymbol{S})$-Cha $\left(v_{\mathrm{N}-\mathrm{H}}=3380 \mathrm{~cm}^{-1}, v_{\text {esterC}=\mathrm{O}}=1725 \mathrm{~cm}^{-1}\right.$ and $\left.v_{\text {amideC }=\mathrm{O}}=1672 \mathrm{~cm}^{-1}\right)$, ii) the increased intensity of the absorption bands corresponding to stacks $\left(v_{\mathrm{N}-\mathrm{H}}=3235 \mathrm{~cm}^{-1}\right.$ and $v_{\text {amideC }=\mathrm{O}}=1645 \mathrm{~cm}^{-1}$ ) and iii) the emergence of a new absorption band at $\mathrm{v}=1745 \mathrm{~cm}^{-1}$ which corresponds to free ester $\mathrm{C}=\mathrm{O}$ functions and thus belongs exclusively to BTA $(\boldsymbol{S})$-Cha molecules incorporated into stacks. The FT-IR spectra of the mixtures with and without $\mathrm{Cu}$ coordinated to $\mathbf{B T A}^{\mathbf{P P h} 2}$ are virtually identical indicating that the presence of the $\mathrm{Cu}$ has little influence on the composition of the co-assemblies. For the determination of the amount of BTA (S)-Cha incorporated into stacks, see below.

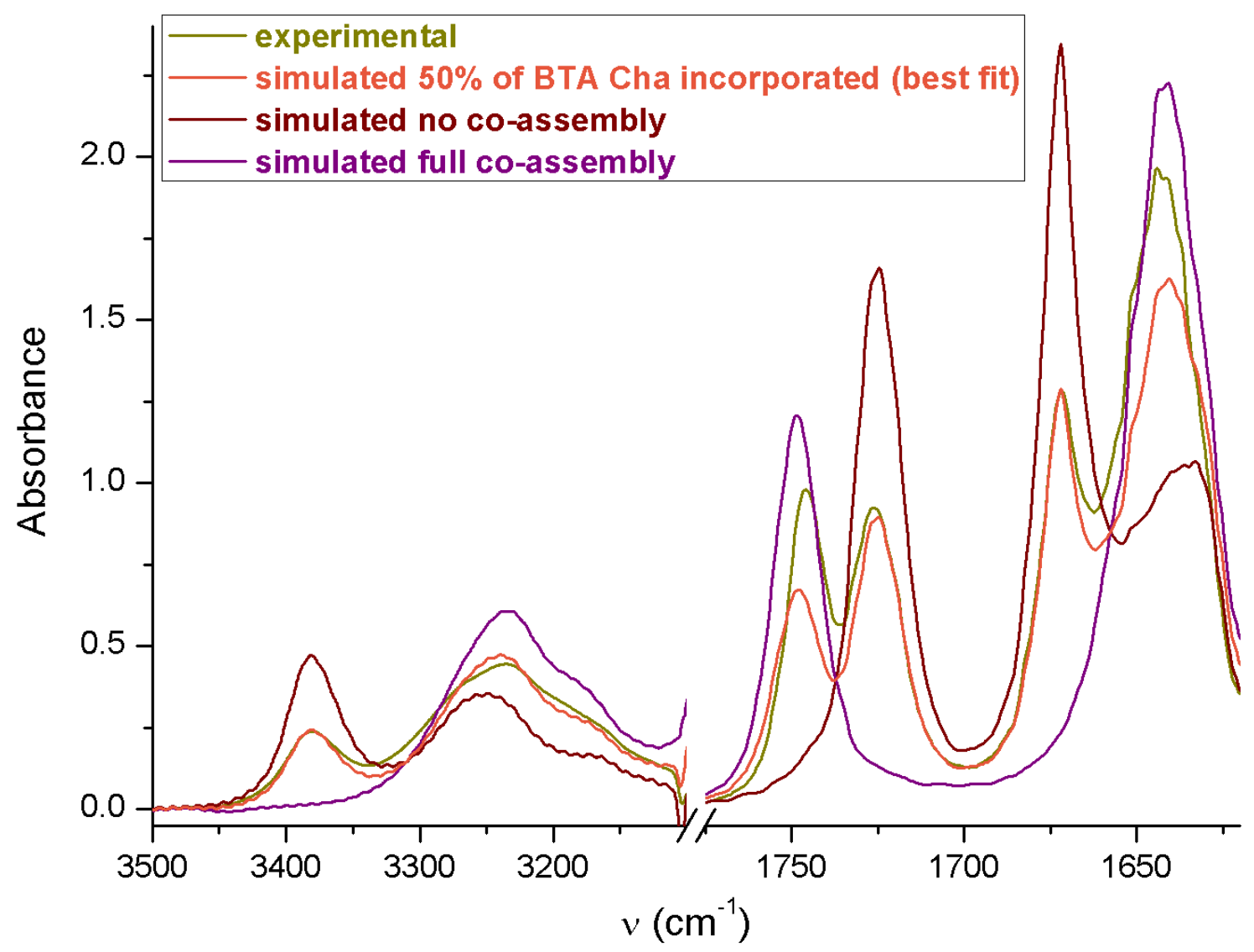

Figure S.4 Quantification of the amount of BTA (S)-Cha present in the co-assemblies. ${ }^{[4]}$ FT-IR analysis of the mixture of $\mathbf{B T A}^{\mathbf{P P h} 2}(16.9 \mathrm{mM})$ and BTA $(\boldsymbol{S})$-Cha $(18.6 \mathrm{mM})$ in toluene at $20^{\circ} \mathrm{C}$. Simulated spectra for the extreme cases for which all or no BTA (S)-Cha is present in the coassemblies. The fraction of BTA (S)-Cha incorporated into stacks (relatively to the amount of BTA (S)-Cha introduced initially, i.e. $18.6 \mathrm{mM}$ ) is $50 \%$ as deduced from the best fit with the simulated FTIR spectra (estimated error 10\%). It means that $~ 35 \%$ of the BTA co-monomers present in the coassemblies are BTA Cha.

* The simulated spectrum of the stacks for the co-assemblies is the weighted average of the contribution of each monomer (BTA $^{\text {PPh2 }}$ and BTA (S)-Cha) present in the stacks. The spectroscopic signature of BTA (S)-Met, ${ }^{[3 a, 3 b]}$ an ester BTA which forms stacks in solution contrarily to BTA (S)-Cha, was selected for the spectrum representing BTA (S)-Cha in the coassemblies. The quality of the fit validates the hypothesis that the conformation of BTA (S)-Cha molecules in the coassembly is similar to that of BTA (S)-Met molecules in the stacks. 


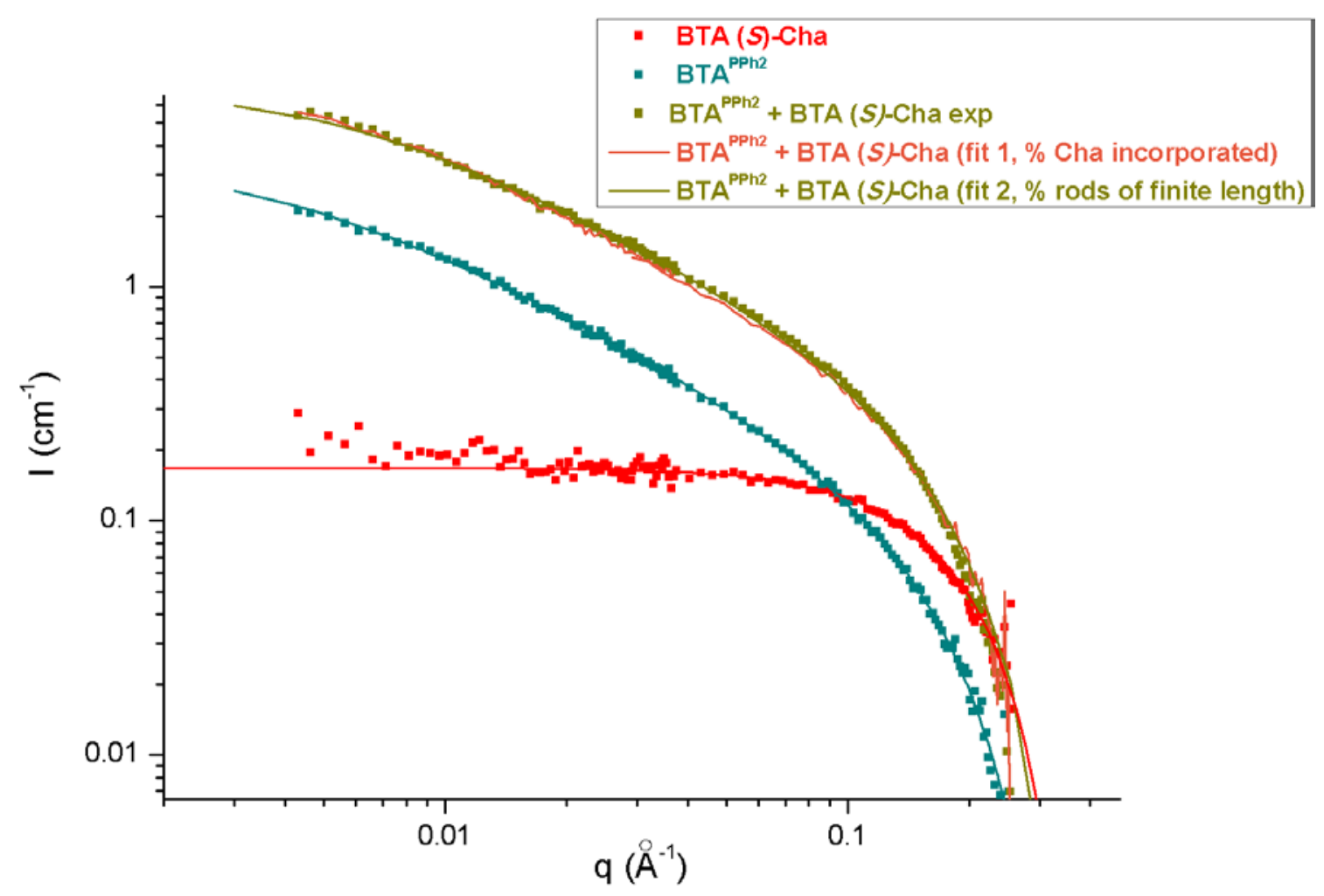

Figure S.5 Characterization by SANS analyses of the composition of the co-assemblies formed

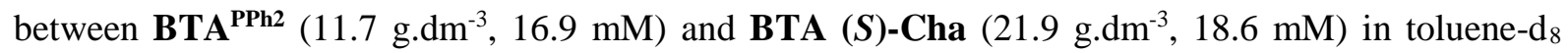
$\left(20^{\circ} \mathrm{C}\right)$.

Fit 1: the experimental curve for the mixture of BTA ${ }^{\mathbf{P P h} 2}$ and BTA $(\boldsymbol{R})$-Cha is fitted according to the hypothesis that BTA $(\boldsymbol{R})$-Cha in part co-assembles with BTA ${ }^{\text {PPh2 }}$ and that the remaining BTA $(\boldsymbol{R})$-Cha exists as dimers. The hypothesis is confirmed by the quality of the fit and by FT-IR analyses presented above (Figure S.4). The fit gives the following results: $67 \%$ of BTA $(\boldsymbol{R})$-Cha is incorporated into stacks. This value is in agreement with that deduced from FT-IR analysis (50 \%, see Figure S.4).

Fit 2: the length of the co-assemblies formed by $\mathbf{B T A}^{\mathbf{P P h} 2}$ and $\mathbf{B T A}(\boldsymbol{R})$-Cha is determined by fitting the SANS analysis with a form factor for rigid rods of finite length with a circular cross-section and a uniform scattering length density. It gives a

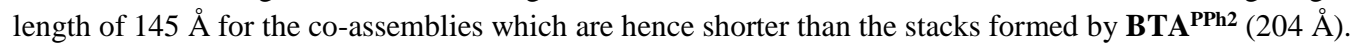

For the results of the fits corresponding to SANS analyses of $\mathbf{B T A}^{\mathbf{P P h} 2}$ and BTA (R)-Cha, see Figures S.1 and S.2 respectively. 


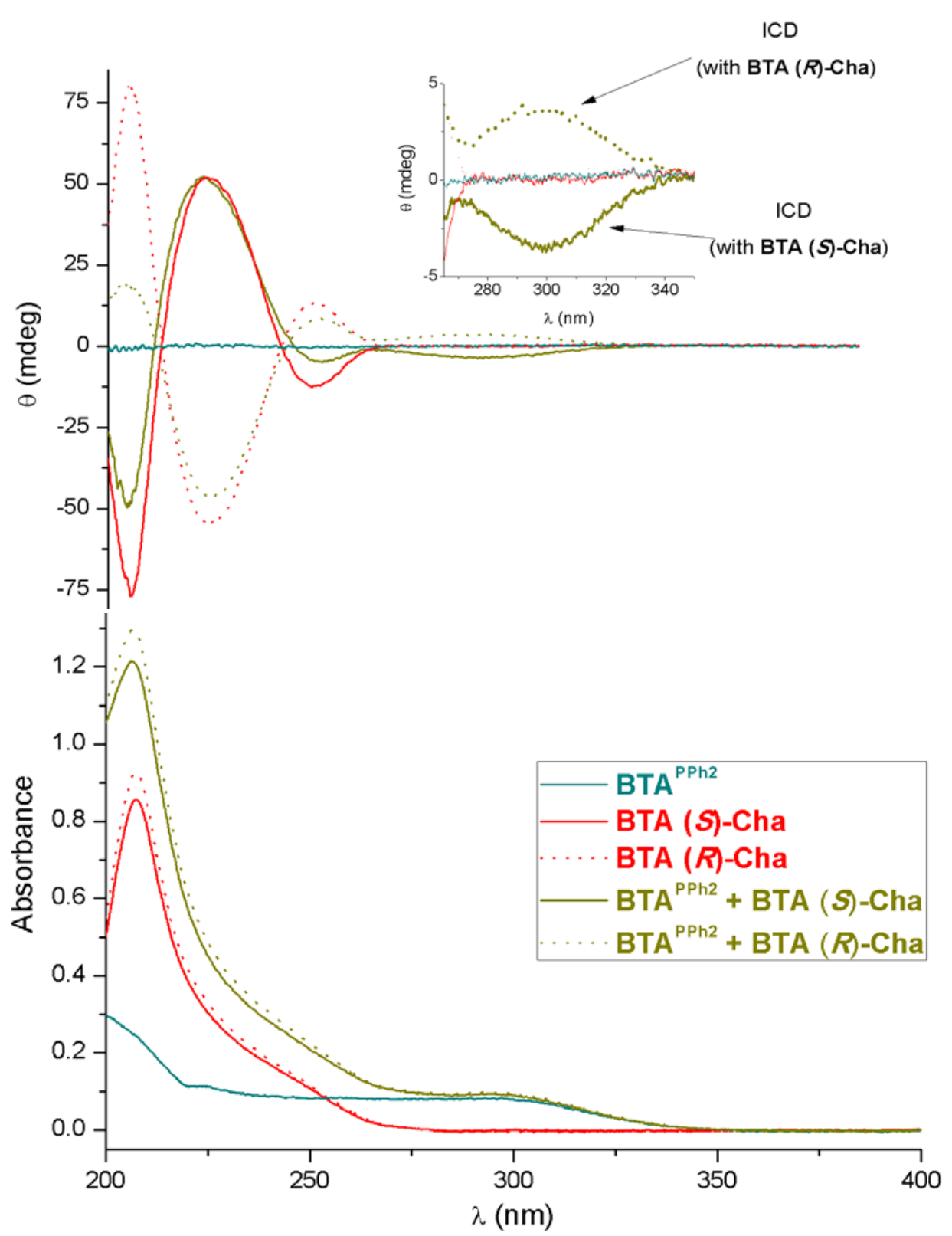

Figure S.6 CD (top) and UV (bottom) analyses of BTA ${ }^{\text {PPh2 }}(0.625 \mathrm{mM})$, of BTA (S)-Cha (1.375 $\mathrm{mM})$, of BTA $(\boldsymbol{R})$-Cha $(1.375 \mathrm{mM})$ and of the mixtures of $\mathbf{B T A}^{\text {PPh2 }}(0.625 \mathrm{mM})$ and BTA (S)-Cha $(1.375 \mathrm{mM})$ and of $\mathbf{B T A}^{\mathbf{P P h} 2}(0.625 \mathrm{mM})$ and BTA $(\boldsymbol{R})$-Cha $(1.375 \mathrm{mM})$ in methylcyclohexane at $20^{\circ} \mathrm{C}$.

CD analyses of BTA (S)-Cha and BTA $(\boldsymbol{R})$-Cha with three maxima in the region of 200-270 $\mathrm{nm}$ are diagnostic of the esterbonded dimers. $^{[3]}$ Mixtures of $\mathbf{B T A}^{\mathbf{P P h} 2}$ and BTA Cha show, in addition to CD signals in the 200-270 nm region, a Cotton effect centered at $\lambda=310 \mathrm{~nm}$, of same intensity but opposite sign depending on the enantiomer of BTA Cha present in the mixture. As only $\mathbf{B T A}^{\mathbf{P P h} 2}$ absorbs in this region, this signal is called an induced CD signal (ICD) ${ }^{[5]}$ and thus indicates that the achiral ligand is located in the chiral environment formed by the helical BTA co-assemblies. Also, enantiomers of BTA Cha are able to fully switch the chirality induced to $\mathbf{B T A}^{\mathbf{P P h} 2}$. 


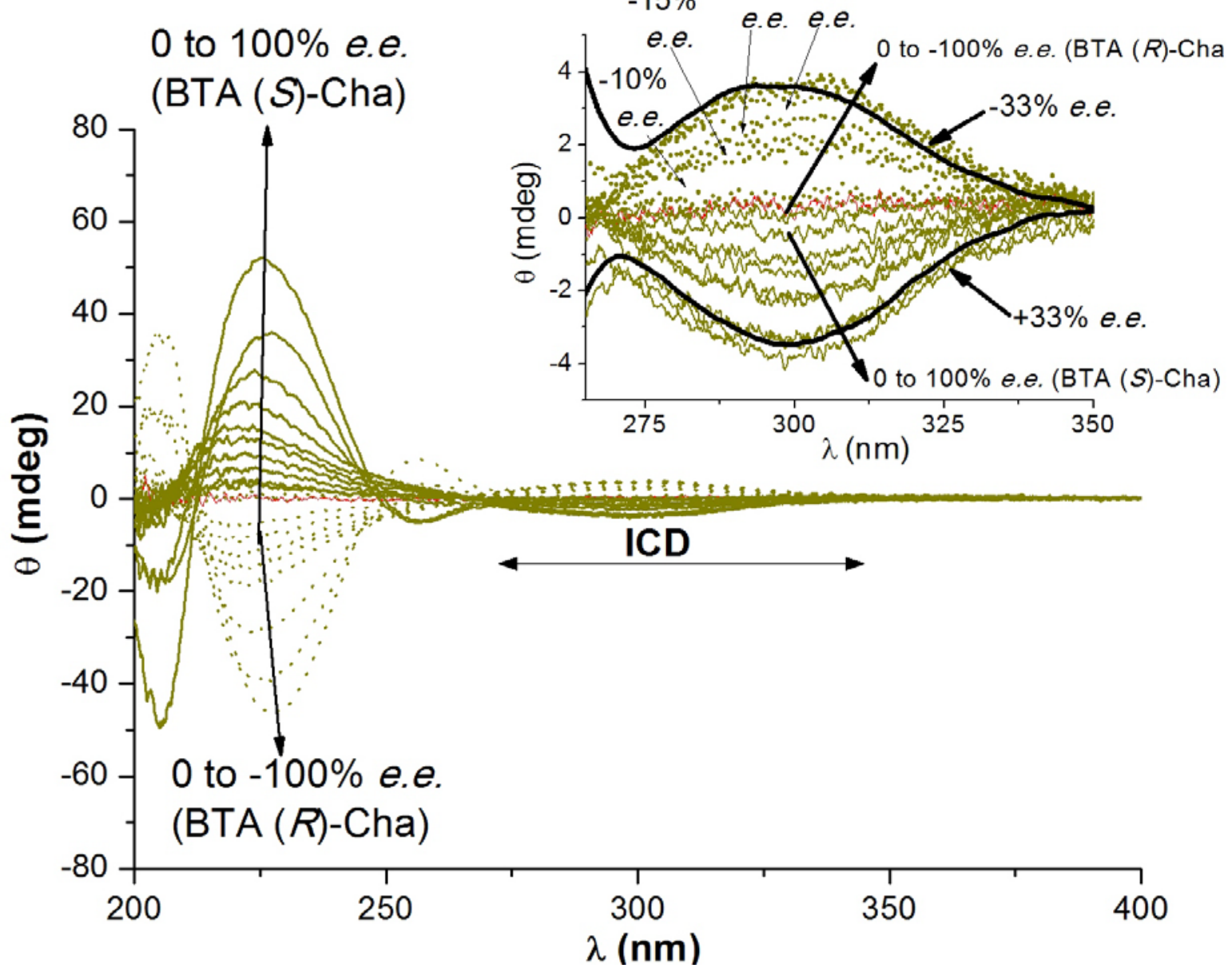

Figure S.7 CD analyses of mixtures of $\mathbf{B T A}^{\mathbf{P P h} 2}(0.625 \mathrm{mM})$ and BTA Cha of various enantiomeric excesses $(1.375 \mathrm{mM})$ in methylcyclohexane at $20^{\circ} \mathrm{C}$. Inset: zoom on the ICD signals.

The mixtures with $+33 \%$ e.e. and $-33 \%$ e.e. have been thickened since a maximum intensity of the ICD signal is reached for these mixtures. $\mathrm{CD}$ analyses were recorded for the following $\mid$ e.e.| in BTA Cha: $0 \%, 2.5 \%, 5 \%, 10 \%, 15 \%, 20 \%$, 25\%, $33 \%, 50 \%, 75 \%$ and $100 \%$. 


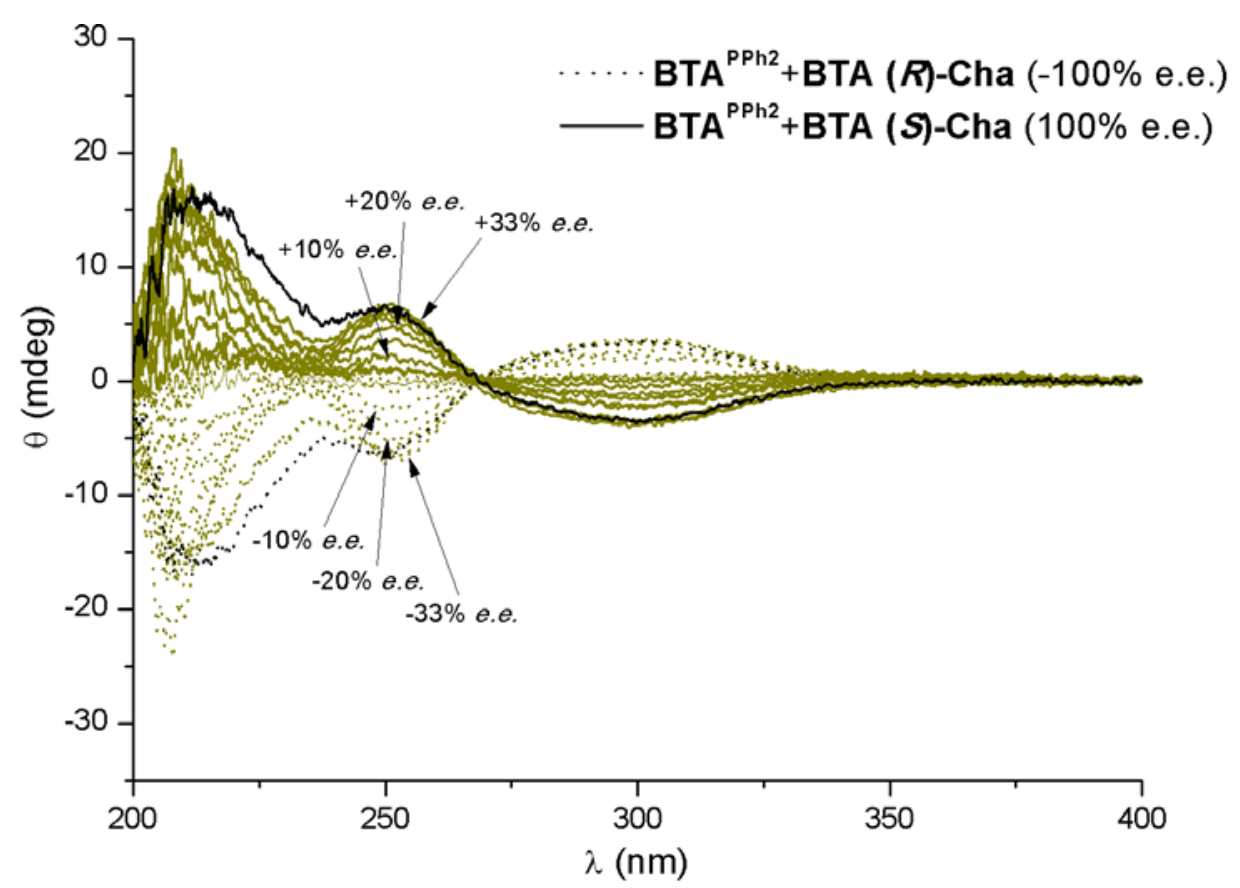

Figure S.8 "Diluted majority rule experiments" of Fig. S.7 processed in order to remove the contribution of BTA Cha dimers to the overall CD signal. The amount of BTA Cha that remains as dimers in the mixtures (conditions indicated in Fig. S.7) has been quantified to $80 \%$ by means of FT-IR analyses (data not shown).

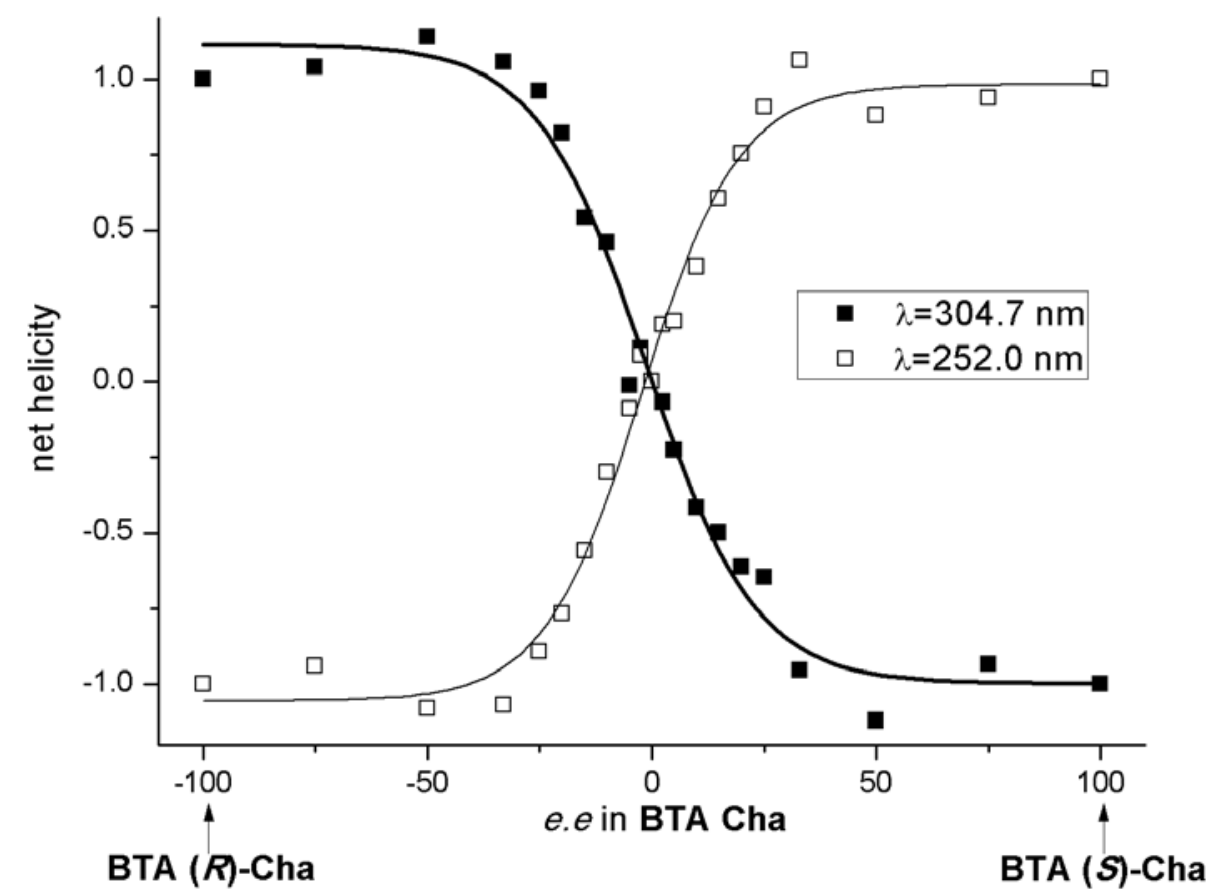

Figure S.9 "Diluted majority rule experiments": Net helicity as a function of the enantiomeric excess of BTA Cha determined according to $\mathrm{CD}$ analyses shown in Figures S.8. The net helicities were obtained by dividing the ellipticities at $\lambda=305 \mathrm{~nm}$ and $\lambda=252 \mathrm{~nm}$ for each mixture by the ellipticities measured for the mixture containing enantiopure BTA Cha. The lines are drawn as a guide to the eye. 


\section{Supplementary Tables, Schemes and Figures: selectivity-switching experiments [Tables S.3 to S.5, Scheme S.1, Figure S.10]}

Table S.3 Copper-catalysed hydrosilylation of 1-(4-nitrophenyl)ethanone with successive additions of substrate and $\mathrm{PhSiH}_{3}$. ${ }^{[a],[b],[c]}$

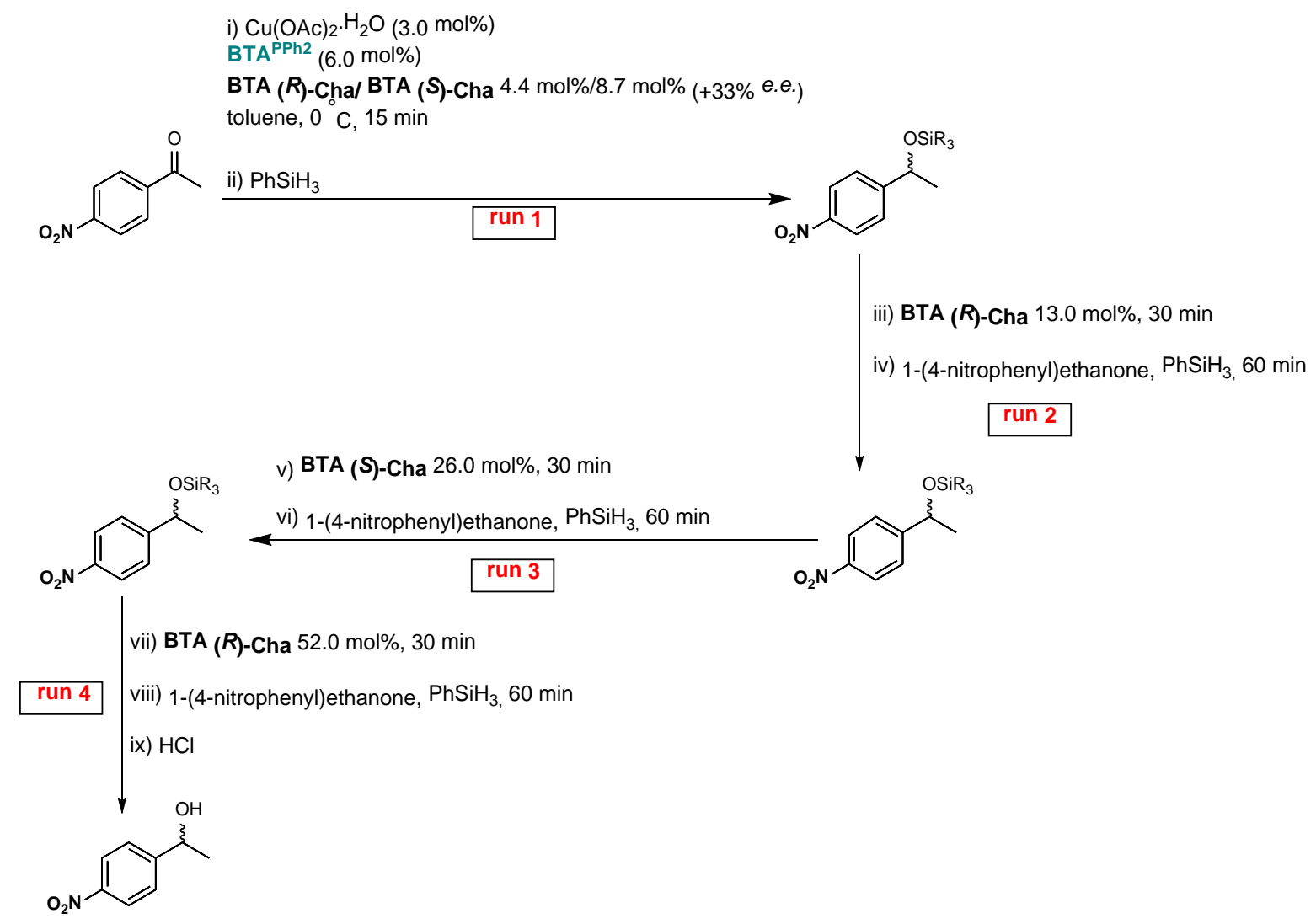

\begin{tabular}{ccccc} 
Run & $\begin{array}{c}\text { BTA (R)-Cha } \\
(\mathrm{mol})\end{array}$ & $\begin{array}{c}\text { BTA (S)-Cha } \\
(\mathrm{mol} \%)\end{array}$ & $\begin{array}{c}\text { obtained e.e. } \\
(\%)\end{array}$ & $\begin{array}{c}\text { e.e. for the } \\
\text { run (\%) }\end{array}$ \\
\hline 1 & 4.4 & 8.7 & $+53(R)$ & $+53(R)$ \\
2 & 17.4 & 8.7 & $-2(S)$ & $-56(S)$ \\
3 & 17.4 & 34.7 & $+17(R)$ & $+53(R)$ \\
4 & 69.4 & 34.7 & 0 & $-52(S)$ \\
\hline
\end{tabular}

[a] Reaction conditions: 1-(4-nitrophenyl)ethanone $\left(4 \times 100 \mathrm{~mol} \%=400 \mathrm{~mol} \%\right.$ in total), $\mathrm{Cu}(\mathrm{OAc}) 2 \cdot \mathrm{H}_{2} \mathrm{O}(3.0 \mathrm{~mol} \%)$, BTA $^{\text {PPh2 }}(6.0 \mathrm{~mol} \%)$, BTA (R)-Cha/BTA (S)-Cha ( $\mid$ e. e. $\left.\mid=33 \%\right), \mathrm{PhSiH}_{3}(200 \mathrm{~mol} \%$ for run 1 and then $100 \mathrm{~mol} \%$ for run 2, run 3 and run $4=500 \mathrm{~mol} \%$ in total), toluene, $0{ }^{\circ} \mathrm{C}$. For the exact amount of BTA Cha present in each run, see the table. Conversion $>99 \%$ was obtained for all runs as determined by GC and ${ }^{1} \mathrm{H}$ NMR analyses. For the GC analyses corresponding to each run see pages S.23 and S.24..

[b] The optimal selectivity for the supramolecular $\mathrm{Cu}$ catalyst under these conditions as determined in Fig. 1a is $63 \%$ e.e. This is the selectivity expected for a catalyst with a fully chirally-amplified helical backbone. In contrast, $21 \%$ e.e. $(0.33 \times$ 63) would be obtained in absence of chirality amplification.

[c] The reaction times for the conversion of the substrate and for the stereochemical switch were not optimized (see Table S.4). 

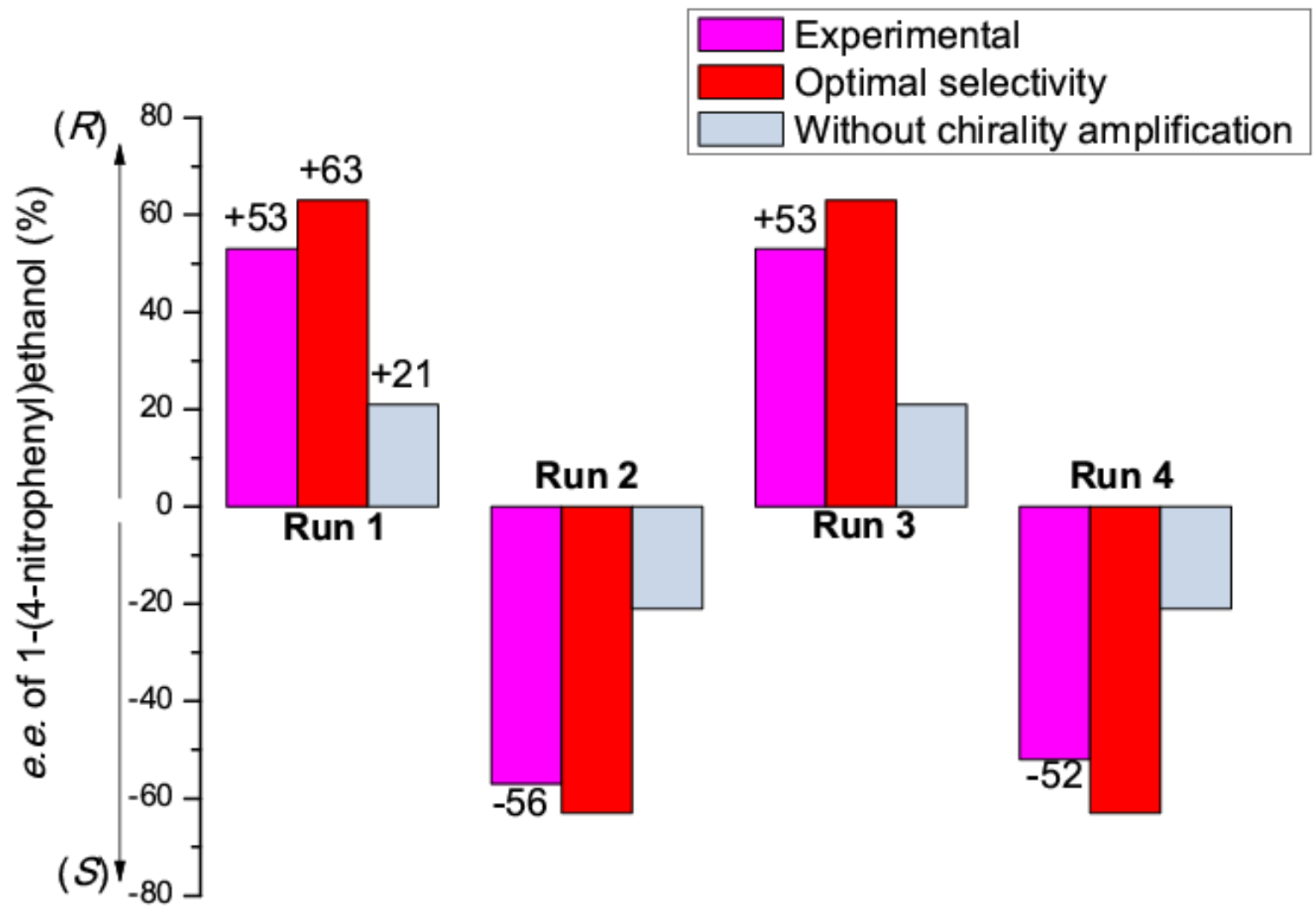

Figure S.10 Copper-catalysed hydrosilylation of 1-(4-nitrophenyl)ethanone with successive additions of substrate and $\mathrm{PhSiH}_{3}$. Comparison of the enantioselectivity of the runs, the optimal selectivity and the selectivity in absence of chirality amplification.

For the conditions and results of the sequential reaction and the definitions of the optimal selectivity and of the selectivity in absence of chirality amplification see the Table S.3. 
Table S.4 Determination of the time required for switching the selectivity for the copper-catalysed hydrosilylation of 1-(4-nitrophenyl)ethanone. ${ }^{[a]}$

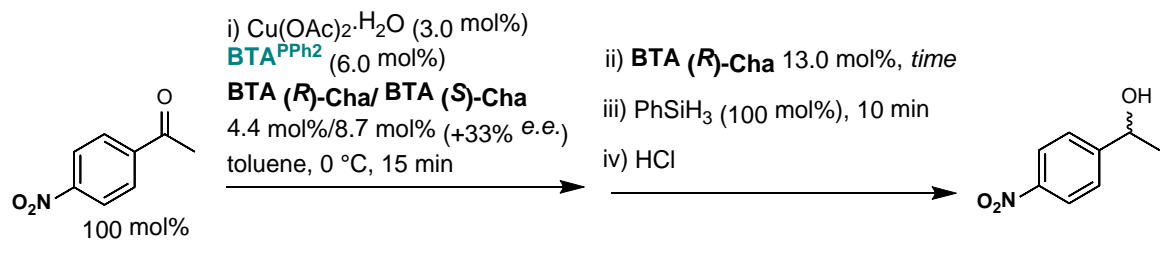

\begin{tabular}{ccc} 
Entry & Time (s) & e.e. $(\%)$ \\
\hline 0 & no BTA (R)-Cha addition & $+60(R)$ \\
1 & 0 & $+17(R)^{[\mathrm{b}]}$ \\
2 & 5 & $-56(S)$ \\
3 & 20 & $-60(S)$ \\
4 & 60 & $-62(S)$
\end{tabular}

[a] Reaction conditions: 1-(4-nitrophenyl)ethanone (100 mol\%), $\mathrm{Cu}(\mathrm{OAc})_{2} \cdot \mathrm{H}_{2} \mathrm{O}(3.0 \mathrm{~mol} \%)$, BTA ${ }^{\text {PPh2 }}$ (6.0 mol\%), BTA (R)Cha/BTA (S)-Cha (4.4 mol\%/8.7 mol\%, +33\% e.e.), toluene, $0{ }^{\circ} \mathrm{C}$. BTA (R)-Cha (13.0 mol\%) was added and then $\mathrm{PhSiH}_{3}$ (100 mol\%) after a given time. Conversion $>99 \%$ was obtained for all entries as determined by GC and ${ }^{1} \mathrm{H}$ NMR analyses. For the GC analyses corresponding to a time of 5 seconds (entry 2) see page S.35.

[b] BTA (R)-Cha and $\mathrm{PhSiH}_{3}$ were mixed together and added together to the precatalytic mixture. In these conditions, the selectivity switch was not complete. It means that the conversion of 1-(4-nitrophenyl)ethanone and the stereochemical switch occur at the same timescale. 
Scheme S.1 Stereochemical switch during the conversion of 1-(4-biphenylyl)ethanone. ${ }^{\text {[a] }}$

a)

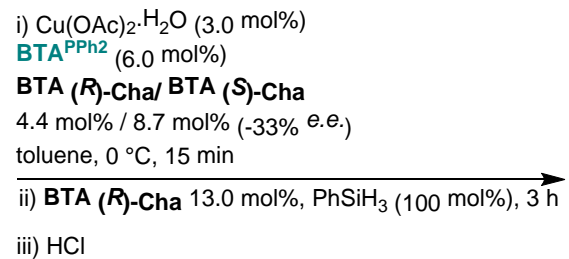

iii) $\mathrm{HCl}$

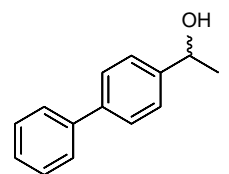

without addition of co-monomer: $+34 \%$ e.e. $(R)$, $85 \%$ conversion with addition of co-monomer: $-43 \%$ e.e. $(S), 72 \%$ conversion

Reaction conditions: 1-(4-biphenylyl)ethanone (100 mol\%), $\mathrm{Cu}(\mathrm{OAc}){ }_{2} \cdot \mathrm{H}_{2} \mathrm{O}(3.0 \mathrm{~mol} \%), \mathbf{B T A}^{\mathbf{P P h} 2}$ (6.0 mol\%), BTA (R)Cha/BTA (S)-Cha (4.4 mol\%/8.7 mol\%, $+33 \%$ e.e.), toluene, $0{ }^{\circ} \mathrm{C}$. BTA (R)-Cha $(13.0 \mathrm{~mol} \%)$ and $\mathrm{PhSiH}_{3}(100 \mathrm{~mol} \%)$ were mixed and added at the same time. The conversion was determined by GC and ${ }^{1} \mathrm{H}$ NMR analyses. For the chiral HPLC analyses with and without switch, see pages S.26 and S.27.

b)

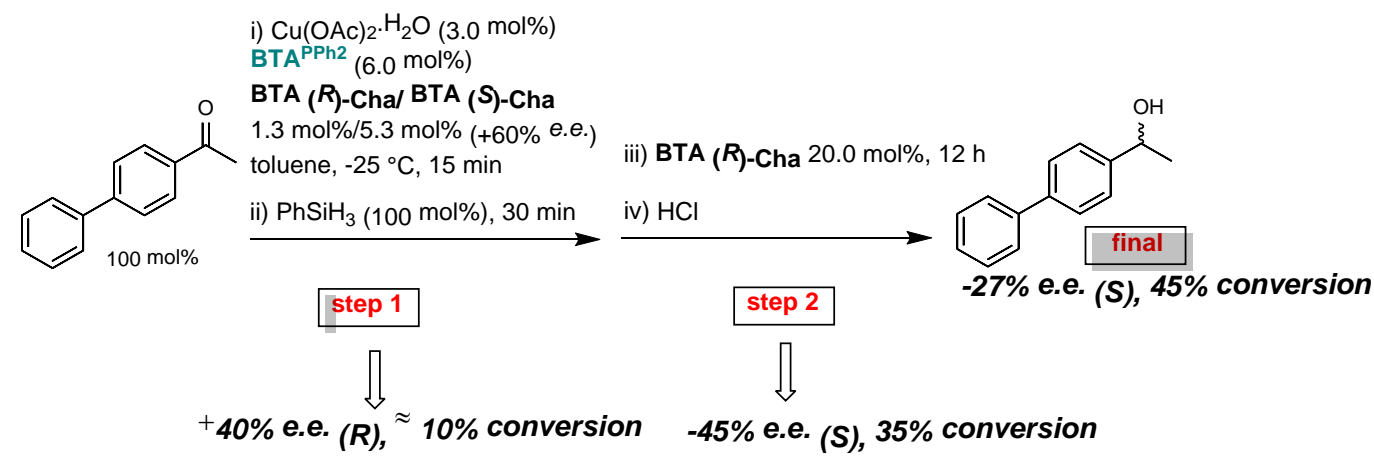

Reaction conditions: 1-(4-biphenylyl)ethanone (100 mol\%), $\mathrm{Cu}(\mathrm{OAc})_{2} \cdot \mathrm{H}_{2} \mathrm{O}(3.0 \mathrm{~mol} \%)$, BTA ${ }^{\mathbf{P P h} 2}$ (6.0 mol\%), BTA (R)Cha/BTA (S)-Cha (1.3 mol\%/5.3 mol\%, $+60 \%$ e.e.), $\mathrm{PhSiH}_{3}(100 \mathrm{~mol} \%)$, toluene, $-25{ }^{\circ} \mathrm{C}$. BTA (R)-Cha (20.0 mol\%) was added after 30 minutes. The conversion was determined by GC and ${ }^{1} \mathrm{H}$ NMR analyses. For the chiral HPLC analyses of step 1 (aliquot) and at the end of the reaction, see page S.28.

[a] The selectivity for step 2 was calculated according to the selectivities and conversions obtained in step 1 and at the end of the reaction. The selectivity of step 2 is optimal and inversed compared to step 1 confirming that full stereochemical switch occurs during the hydrosilylation of 1-(4-biphenylyl)ethanone. 
Table S.5 Copper-catalysed hydrosilylation of 1:1 mixture of 1-(4-nitrophenyl)ethanone and 1-(4biphenylyl)ethanone. ${ }^{[a]}$<smiles>CC(=O)c1ccc(-c2ccccc2)cc1</smiles>

entry 2 i) $\mathrm{Cu}(\mathrm{OAc})_{2} \cdot \mathrm{H}_{2} \mathrm{O}(3.0 \mathrm{~mol} \%)$

$\mathrm{BTA}^{\mathrm{PPh} 2}(6.0 \mathrm{~mol} \%)$

BTA (S)-Cha (6.6 mol\%)

toluene, $-25^{\circ} \mathrm{C}, 15 \mathrm{~min}$

ii) $\mathrm{PhSiH}_{3}(100 \mathrm{~mol} \%), 12 \mathrm{~h}$

iii) $\mathrm{HCl}$<smiles>C[C@H](O)c1ccc(-c2ccccc2)cc1</smiles><smiles>CC(=O)c1ccc(-c2ccccc2)cc1</smiles>

i) $\mathrm{Cu}(\mathrm{OAc}) 2 \cdot \mathrm{H}_{2} \mathrm{O}(3.0 \mathrm{~mol} \%)$

BTA $^{\text {PPh2 }}$ (6.0 mol\%)

BTA $(\boldsymbol{R})$-Cha (6.6 mol\%)

toluene, -25 C, $15 \mathrm{~min}$

ii) $\mathrm{PhSiH}_{3}(100 \mathrm{~mol} \%), 12 \mathrm{~h}$<smiles>CC(O)c1ccc(-c2ccccc2)cc1</smiles>

iii) $\mathrm{HCl}$<smiles>CC(=O)c1ccc(-c2ccccc2)cc1</smiles>

$100 \mathrm{~mol} \%$ i) $\mathrm{Cu}(\mathrm{OAc}) 2 \cdot \mathrm{H}_{2} \mathrm{O}(3.0 \mathrm{~mol} \%)$ $\mathrm{BTA}^{\mathrm{PPh} 2}(6.0 \mathrm{~mol} \%)$ BTA $(R)$-Chal BTA (S)-Cha $1.3 \mathrm{~mol} \% / 5.3 \mathrm{~mol} \%$ (+60\% e.e.) toluene, $-25^{\circ} \mathrm{C}, 15 \mathrm{~min}$ ii) $\mathrm{PhSiH}_{3}$ (200 mol\%), $2 \mathrm{~min}$ step 1<smiles>CC(O)c1ccc(-c2ccccc2)cc1</smiles><smiles>CC(=O)c1ccc(-c2ccccc2)cc1</smiles>
i) $\mathrm{Cu}(\mathrm{OAc}) 2 \cdot \mathrm{H}_{2} \mathrm{O}(3.0 \mathrm{~mol} \%)$ $\operatorname{BTA}^{\mathrm{PPh} 2}(6.0 \mathrm{~mol} \%)$ BTA $(R)$-Chal BTA ( $S$ )-Cha $5.3 \mathrm{~mol} \% / 1.3 \mathrm{~mol} \%$ (-60\% e.e.) toluene, $-25^{\circ} \mathrm{C}, 15 \mathrm{~min}$ ii) $\mathrm{PhSiH}_{3}$ (200 mol\%), 2 min step 1

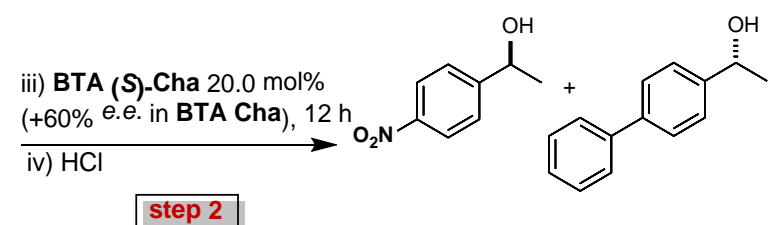

\begin{tabular}{|c|c|c|c|c|c|c|}
\hline & \multicolumn{2}{|c|}{$1^{\text {st }}$ step } & \multicolumn{2}{|c|}{$2^{\text {nd }}$ step } & \multicolumn{2}{|c|}{ e.e. (\%) } \\
\hline Entry & $\begin{array}{c}\text { BTA (R)-Cha } \\
(\mathrm{mol} \%)\end{array}$ & $\begin{array}{c}\text { BTA (S)-Cha } \\
(\mathrm{mol} \%)\end{array}$ & $\begin{array}{c}\text { BTA (R)-Cha } \\
(\mathrm{mol} \%)\end{array}$ & $\begin{array}{c}\text { BTA (S)-Cha } \\
(\mathrm{mol} \%)\end{array}$ & $4-\mathrm{NO}_{2}$ & 4-Ph \\
\hline 1 & \multicolumn{4}{|c|}{ BTA (S)-Cha (6.6) } & $+77(R)$ & $+38(R)$ \\
\hline 2 & \multicolumn{4}{|c|}{ BTA (R)-Cha (6.6) } & $-79(S)$ & $-45(S)$ \\
\hline 3 & 1.3 & 5.3 & 21.3 & 5.3 & $+74(R)$ & $-34(S)$ \\
\hline 4 & 5.3 & 1.3 & 5.3 & 21.3 & $-69(S)$ & $+30(R)$ \\
\hline
\end{tabular}

[a] Reaction conditions: 1-(4-nitrophenyl)ethanone (50 mol\%, entries 1 and 2, 100 mol\% entries 3 and 4), 1-(4biphenylyl)ethanone (50 mol\% entries 1 and 2, 100 mol\% entries 3 and 4), $\mathrm{Cu}(\mathrm{OAc})_{2} \cdot \mathrm{H}_{2} \mathrm{O}(3.0 \mathrm{~mol} \%)$, BTA ${ }^{\text {PPh2 }}(6.0$ mol\%), enantiopure BTA Cha (entries 1 and 2) or BTA (R)-Cha/BTA (S)-Cha ( $\mid$ e. e. $\mid=\mathbf{6 0} \%$, entries 3 and 4), $\mathrm{PhSiH}_{3}$ (100 mol\% entries 1-2, 200 mol\% entries 3-4), toluene, $-25^{\circ} \mathrm{C}$. For the exact amount of BTA Cha present in each step, see the table. The conversion was determined by GC and ${ }^{1} \mathrm{H}$ NMR analyses. Conversion of 1-(4-nitrophenyl)ethanone was superior to $99 \%$ for all entries. Conversion of 1-(4-biphenylyl)ethanone was of $84 \%$ and $60 \%$ for entries 3 and 4 respectively. The optical purity of 1-(4-nitrophenyl)ethanol and 1-(4-biphenylyl)ethanol was determined by chiral GC and chiral HPLC analyses, respectively. For chiral GC analyses of entries 1-4, see pages S.30 and S.31. 


\section{General Procedures.}

Preparation of new compounds: The synthetic procedure for the preparation of $\mathbf{B T A} \mathbf{A}^{\mathbf{P P h} 2}$ is detailed below. N,N-dimethylaminopyridine (DMAP), N-(3-dimethylaminopropyl)-N'ethylcarbodiimide hydrochloride $(\mathrm{EDC} \cdot \mathrm{HCl})$, phenylsilane, $\mathrm{Cu}(\mathrm{OAc})_{2} \cdot \mathrm{H}_{2} \mathrm{O}, \quad$ 1-(4nitrophenyl)ethanone and 1-(4-biphenylyl)ethanone were acquired from commercial suppliers and used directly. 3,5-bisoctylaminocarbonyl-benzoic acid, ${ }^{[6]}$ 4-diphenylphosphinoaniline, ${ }^{[7]}$ BTA (S)-Val, ${ }^{[4]}$ BTA (S)-Tle, ${ }^{[4]}$ BTA (S)-Leu, ${ }^{[4]}$ BTA (S)-Ile, ${ }^{[4]}$ BTA (S)-Cha ${ }^{[3 b]}$ and BTA (R)-Cha ${ }^{[3 b]}$ were prepared following published procedures. Racemic phenyl alcohols were prepared by reduction of the corresponding aromatic ketones with $\mathrm{NaBH}_{4}$ in methanol. Solvents for catalytic experiments were obtained from an SPS solvent purification system (ITInc). Chromatography-grade solvents were used for samples analysed by FT-IR and CD spectroscopy. NMR spectra were recorded on a Bruker Avance 300 spectrometer and calibrated to the residual solvent peak: DMSO- $\mathrm{d}_{6}\left({ }^{1} \mathrm{H}: 2.50 \mathrm{ppm} ;{ }^{13} \mathrm{C}: 39.52 \mathrm{ppm}\right)$. Peaks are reported with their corresponding multiplicity (s: singlet; d: doublet, t: triplet; m: multiplet) and integration, and respective $J$ coupling constants are given in Hertz. Exact mass measurements (HRMS) were obtained on TQ R30-10 HRMS spectrometer by ESI+ ionization and are reported in $\mathrm{m} / \mathrm{z}$ for the major signal.

Chiral GC and HPLC analyses: 1-(4-nitrophenyl)ethanol. The optical purity was determined by GC analysis: Chiral Cyclosil-B column, $30 \mathrm{~m} \times 250 \mu \mathrm{m} \times 0.25 \mu \mathrm{m}$, inlet pressure $=12.6$ psi. Injection temperature $=220^{\circ} \mathrm{C}$; detector temperature $=300^{\circ} \mathrm{C}$; column temperature $=$ $165^{\circ} \mathrm{C}$. Retention time: $8.6 \mathrm{~min}$ (1-(4-nitrophenyl)ethanone), $18.9 \mathrm{~min}((R)$-enantiomer), 19.3 min ((S)-enantiomer). ${ }^{[8]}$ 1-(4-biphenylyl)ethanol. The optical purity was determined by HPLC analysis: Chiralpak AD-H column, heptane/isopropanol 97/3, flow=1 mL.min ${ }^{-1}$, detection at $254 \mathrm{~nm}$. Retention time: $17.8 \mathrm{~min}((S)$-enantiomer) and $20.2 \mathrm{~min}((R)$ enantiomer). ${ }^{[9]}$ Mixture of 1-(4-nitrophenyl)ethanol and 1-(4-biphenylyl)ethanol. GC analysis: Chiral Cyclosil-B column, $30 \mathrm{~m} \times 250 \mu \mathrm{m} \times 0.25 \mu \mathrm{m}$, inlet pressure $=12.6$ psi. Injection temperature $=220^{\circ} \mathrm{C}$; detector temperature $=300^{\circ} \mathrm{C}$; column temperature $=165^{\circ} \mathrm{C}$ for $25 \mathrm{~min}$, then $180^{\circ} \mathrm{C}$ for $20 \mathrm{~min}$. Retention time: $18.9 \mathrm{~min}$ (1-(4-nitrophenyl)ethanol, $(R)$ enantiomer), $19.3 \mathrm{~min}$ (1-(4-nitrophenyl)ethanol, $(S)$-enantiomer), $29.6 \mathrm{~min}$ (1-(4biphenylyl)ethanol, (R)-enantiomer), 29.9 min (1-(4-biphenylyl)ethanol, (S)-enantiomer).

Preparation of BTA solutions for analyses: the desired BTA was weighed into a $ø 11.6 \mathrm{~mm}$ HPLC vial or a ø20 mm glass vial, the volume of solvent was adjusted to the desired end 
concentration with an adequate glass microsyringe, and verified by weighing the sample. Vials were sealed with PTFE-coated caps to avoid contamination from leaching plasticizer.

Fourier-Transform Infrared (FT-IR) analyses: FT-IR measurements were performed on a Nicolet iS10 spectrometer. Solution spectra were measured in $\mathrm{CaF}_{2}$ cells by adjusting the pathlength $(0.1 \mathrm{~cm}$ or $0.05 \mathrm{~cm})$ to the concentration and were corrected for air, solvent and cell absorption.

Circular dichroism (CD) analyses: CD measurements were performed on a Jasco J-1500 spectrometer equipped with a Peltier thermostated cell holder and Xe laser. Data were recorded at $20^{\circ} \mathrm{C}$ with the following parameters: $20 \mathrm{~nm} \cdot \mathrm{min}^{-1}$ sweep rate, $0.1 \mathrm{~nm}$ data pitch, $2.0 \mathrm{~nm}$ bandwidth, and between 400 and $200 \mathrm{~nm}$. Spectra were corrected for solvent and cell contribution. A $0.1 \mathrm{~mm}$ dismountable quartz cell $\left(2 \times 10^{-3} \mathrm{M}\right)$ was used. For all samples, LD contribution was negligible $(\triangle \mathrm{LD}<0.005 \mathrm{dOD})$ and the shape of the $\mathrm{CD}$ signal was independent of the orientation of the quartz slide.

UV-Vis analyses: UV-Vis absorption spectra were extracted from CD on each of the above samples and obtained after correction of the absorption of air, solvent, and cell at the same temperature.

Small-angle neutron scattering (SANS) analyses: SANS measurements were made at the LLB (Saclay, France) on the PA20 instrument, at two distance-wavelength combinations to cover the $4.2 \times 10^{-3}$ to $0.25 \AA^{-1} q$-range, where the scattering vector $q$ is defined as usual, assuming elastic scattering, as $q=(4 \pi / \lambda) \sin (\theta / 2)$, where $\theta$ is the angle between incident and scattered beam. Data were corrected for the empty cell signal and the solute and solvent incoherent background. A light water standard was used to normalize the scattered intensities to $\mathrm{cm}^{-1}$ units. 


\section{Synthetic procedures.}

Synthesis of BTA $^{\text {PPh2: 3,5-bisoctylaminocarbonyl-benzoic acid }}{ }^{[6]}$ (1.50 g, 3.5 mmol) and dry THF (100 mL) were mixed in an oven-dried Schlenk flask under argon and then N,Ndimethylaminopyridine (0.72 g, $5.9 \quad \mathrm{mmol}), \quad \mathrm{N}$-(3-Dimethylaminopropyl)-N'ethylcarbodiimide hydrochloride (1.13 g, $5.9 \mathrm{mmol})$ and 4-diphenylphosphinoaniline ${ }^{[7]}$ (1.44 g, $5.2 \mathrm{mmol}$ ) were added as solids. The reaction mixture was refluxed for 2 days. After cooling to room temperature, the mixture was evaporated under vacuum and the crude product was purified by column chromatography on silica gel eluting with DCM/AcOEt (95/5 to $7 / 1$ ) to yield $\mathbf{B T A}^{\mathbf{P P h} 2}$ (1.90 g, $79 \%$ ) as a colourless solid. ${ }^{\mathbf{1}} \mathbf{H}$ NMR (300 MHz, DMSO-d 6 ) $\delta 10.62$ (s, 1H), 8.68 (t, $J=5.6 \mathrm{~Hz}, 2 \mathrm{H}), 8.45$ (dd, $J=7.7,1.6 \mathrm{~Hz}, 3 \mathrm{H}), 7.84$ (d, $J=8.1 \mathrm{~Hz}$, 2H), 7.46-7.37 (m, 6H), 7.31-7.21 (m, 6H), 3.29-3.22 (m, 4H), 1.61-1.47 (m, 4H), 1.36-1.11 (m, 20H), 0.90-0.79 (m, 6H). ${ }^{31} \mathbf{P}\left\{{ }^{1} \mathbf{H}\right\}$ NMR (122 MHz, DMSO-d 6$) \delta$-7.7. ${ }^{13} \mathbf{C}\left\{{ }^{1} \mathbf{H}\right\}$ NMR (75 MHz, DMSO-d 6 ) $\delta 165.2,165.0,139.9,137.0(\mathrm{~d}, J=11.4 \mathrm{~Hz}), 135.2,135.1,134.1(\mathrm{~d}, J=$ $20.6 \mathrm{~Hz}$ ), 133.1 (d, $J=19.4 \mathrm{~Hz}$ ), 129.0, 128.9, 128.8, 128.7 (d, $J=6.8 \mathrm{~Hz}), 120.4$ (d, $J=7.4$ Hz), 39.6 (below the solvent peak), 31.3, 29.0, 28.8, 28.7, 26.5, 22.1, 13.9. HRMS: Calculated for $\mathrm{C}_{43} \mathrm{H}_{55} \mathrm{~N}_{3} \mathrm{O}_{3} \mathrm{P}[\mathrm{M}+\mathrm{H}]^{+}$: 692.3976, found: 692.3973. 


\section{Catalytic experiments.}

Catalytic screening (Tables 1 and S.1): An oven-dried test tube was loaded with $\mathrm{Cu}(\mathrm{OAc})_{2} \cdot \mathrm{H}_{2} \mathrm{O}(1.0 \mathrm{mg}, 3.0 \mathrm{~mol} \%)$ and $\mathbf{B T A}^{\mathbf{P P h} 2}(6.9 \mathrm{mg}, 6.0 \mathrm{~mol} \%)$ in dry THF $(500 \mu \mathrm{L})$ and the mixture was stirred for 30 minutes. The solvent was removed under vacuum and the test tube was further put under vacuum $\left(1.10^{-3} \mathrm{mbar}\right)$ for 1 hour. 1-(4-nitrophenyl)ethanone (28.0 mg, $0.17 \mathrm{mmol}$ ) was added before flushing the tube with argon for 10 seconds. The BTA co-monomer (6.6 mol\% in $200 \mu \mathrm{L}$ of dry toluene) was added to the test tube as well as dry toluene in order to get a total volume of $590 \mu \mathrm{L}$. The mixture was stirred for $15 \mathrm{~min}$ at room temperature. $\mathrm{PhSiH}_{3}(21.0 \mu \mathrm{L}, 0.17 \mathrm{mmol})$ was added to the test tube and the mixture was stirred for 17 hours. Typical work-up: Aqueous solution of $\mathrm{HCl}(10 \mathrm{wt} \%, 400 \mu \mathrm{L})$ was added and the mixture was stirred for $30 \mathrm{~min}$ (until the solution became transparent). Then, the products were extracted with $\mathrm{Et}_{2} \mathrm{O}(3 \mathrm{x} 1 \mathrm{~mL})$ and AcOEt $(1 \times 1 \mathrm{~mL})$ and the solvents were evaporated under vacuum. The residue was taken up in DCM and passed through a silica plug eluting with DCM. The solvents were evaporated and the conversion and enantioselectivity were determined by ${ }^{1} \mathrm{H}$ NMR and chiral GC respectively.

Screening for chirality amplification (Table S.2): An oven-dried test tube was loaded with $\mathrm{Cu}(\mathrm{OAc})_{2} \cdot \mathrm{H}_{2} \mathrm{O}(1.0 \mathrm{mg}, 3.0 \mathrm{~mol} \%)$ and $\mathbf{B T A}^{\mathbf{P P h} 2}$ (6.9 mg, $\left.6.0 \mathrm{~mol} \%\right)$ in dry THF $(500 \mu \mathrm{L})$ and the mixture was stirred for 30 minutes. The solvent was removed under vacuum and the test tube was further put under vacuum $\left(1.10^{-3} \mathrm{mbar}\right)$ for 1 hour. 1-(4-nitrophenyl)ethanone (28.0 mg, $0.17 \mathrm{mmol}$ ) was added before flushing the tube with argon for 10 seconds. A 25\% e.e. scalemic mixture biased in favour of BTA (R)-Cha (x mol\%) in $200 \mu \mathrm{L}$ of toluene was added to the test tube as well as dry toluene in order to get a total volume of $590 \mu \mathrm{L}$. The mixture was stirred for $15 \mathrm{~min}$ at room temperature. The mixture was cooled to the desired temperature and further stirred for $15 \mathrm{~min}$. $\mathrm{PhSiH}_{3}(21.0 \mu \mathrm{L}, 0.17 \mathrm{mmol})$ was added to the test tube and the mixture was stirred until completion of the reaction. The typical work-up procedure was followed.

Chirality amplification effect under optimized conditions (Figure 1a): An oven-dried test tube was loaded with $\mathrm{Cu}(\mathrm{OAc})_{2} \cdot \mathrm{H}_{2} \mathrm{O}(1.0 \mathrm{mg}, 3.0 \mathrm{~mol} \%)$ and $\mathbf{B T A}^{\mathbf{P P h} 2}$ (6.9 mg, $\left.6.0 \mathrm{~mol} \%\right)$ in dry THF $(500 \mu \mathrm{L})$ and the mixture was stirred for 30 minutes. The solvent was removed under vacuum and the test tube was further put under vacuum $\left(1.10^{-3} \mathrm{mbar}\right)$ for 1 hour. 1-(4nitrophenyl)ethanone ( $28.0 \mathrm{mg}, 0.17 \mathrm{mmol}$ ) was added before flushing the tube with argon for 10 seconds. A scalemic mixture of BTA Cha (25.8 mg, $13.2 \mathrm{~mol} \%$, $\mathrm{x} \%$ e.e.) in $200 \mu \mathrm{L}$ of toluene was added to the test tube as well as dry toluene in order to get a total volume of 590 
$\mu \mathrm{L}$. The mixture was stirred for $15 \mathrm{~min}$ at room temperature. The mixture was cooled to $0{ }^{\circ} \mathrm{C}$ and further stirred for $15 \mathrm{~min} . \mathrm{PhSiH}_{3}(21.0 \mu \mathrm{L}, 0.17 \mathrm{mmol})$ was added to the test tube and the mixture was stirred until completion of the reaction. The typical work-up procedure was followed.

Hydrosilylation of 1-(4-nitrophenyl)ethanone with sequential additions of substrate and $\underline{\mathrm{PhSiH}}_{3}$ (Table S.3, Figures $1 \mathrm{~b}$ and S.10): A Schlenk tube tube was loaded with $\mathrm{Cu}(\mathrm{OAc})_{2} \cdot \mathrm{H}_{2} \mathrm{O}$ (1.0 mg, $\left.3.0 \mathrm{~mol} \%\right)$ and $\mathbf{B T A}^{\mathbf{P P h} 2}$ (6.9 mg, $\left.6.0 \mathrm{~mol} \%\right)$ in dry THF (500 $\left.\mu \mathrm{L}\right)$ and the mixture was stirred for 30 minutes. The solvent was removed under vacuum and the Schlenk tube was further put under vacuum $\left(1.10^{-3}\right.$ mbar $)$ for 1 hour. Then 1-(4nitrophenyl)ethanone (28.0 mg, $0.17 \mathrm{mmol}$ ) was added before flushing the tube with argon for 10 seconds. BTA (R)-Cha (8.6 mg, $4.4 \mathrm{~mol} \%)$ and BTA (S)-Cha (17.2 mg, $8.7 \mathrm{~mol} \%)$ in 80 $\mu \mathrm{L}$ of dry toluene was added to the Schlenk tube as well as dry toluene in order to get a total volume of $590 \mu \mathrm{L}$. The mixture was stirred for $15 \mathrm{~min}$ at room temperature. The mixture was cooled to $0{ }^{\circ} \mathrm{C}$ and further stirred for $15 \mathrm{~min}$. $\mathrm{PhSiH}_{3}(42.0 \mu \mathrm{L}, 0.34 \mathrm{mmol})$ was added and the mixture was stirred for 15 minutes. An aliquot was taken up, hydrolyzed with aqueous $\mathrm{HCl}$ and analyzed by chiral GC (run 1). Then, BTA (R)-Cha (25.4 mg, $13.0 \mathrm{~mol} \%$ ) in $200 \mu \mathrm{L}$ of toluene was added and the mixture was stirred for 30 min before addition of 1-(4nitrophenyl)ethanone (28.0 mg, $0.17 \mathrm{mmol}$ ) and $\mathrm{PhSiH}_{3}(21.0 \mu \mathrm{L}, 0.17 \mathrm{mmol})$. The mixture was stirred for 60 minutes and an aliquot was taken up, hydrolyzed with aqueous $\mathrm{HCl}$ and analyzed by chiral GC (run 2). Then, BTA (S)-Cha (50.7 mg, $26.0 \mathrm{~mol} \%$ ) in $100 \mu \mathrm{L}$ of toluene was added and the mixture was stirred for 30 min before addition of 1-(4nitrophenyl)ethanone (28.0 mg, $0.17 \mathrm{mmol})$ and $\mathrm{PhSiH}_{3}(21.0 \mu \mathrm{L}, 0.17 \mathrm{mmol})$. The mixture was stirred for 60 minutes and an aliquot was taken up, hydrolyzed with aqueous $\mathrm{HCl}$ and analyzed by chiral GC (run 3). Then, BTA (R)-Cha (100.0 mg, $52.0 \mathrm{~mol} \%$ ) in $200 \mu \mathrm{L}$ of toluene was added and the mixture was stirred for $30 \mathrm{~min}$ before addition of 1-(4nitrophenyl)ethanone (28.0 mg, $0.17 \mathrm{mmol})$ and $\mathrm{PhSiH}_{3}(21.0 \mu \mathrm{L}, 0.17 \mathrm{mmol})$. The mixture was stirred for 60 minutes and the typical work-up procedure was followed (run 4). 
Table S.6 Determination of the enantiomeric excess in 1-(4-nitrophenyl)ethanol for each run of for the sequential copper-catalysed hydrosilylation of 1-(4-nitrophenyl)ethanone.

\begin{tabular}{ccccc} 
run & $\begin{array}{c}\text { e.e.from the } \\
\text { aliquots }^{[\mathrm{a}]}\end{array}$ & $\begin{array}{c}\text { eq. of }(R) /(S) \\
\text { product }^{[\mathrm{b}]}\end{array}$ & $\begin{array}{c}\text { e.r. for the } \\
\text { run }\end{array}$ & $\begin{array}{c}\text { e.e. for the } \\
\text { run }\end{array}$ \\
\hline 1 & $53 \%$ & $0.765 / 0.235$ & $76.5 / 23.5$ & $53 \%$ \\
2 & $-2 \%$ & $0.984 / 1.016$ & $22.0 / 78.0$ & $-56 \%$ \\
3 & $17 \%$ & $1.75 / 1.25$ & $76.5 / 23.5$ & $53 \%$ \\
4 & $-1 \%$ & $1.99 / 2.01$ & $24.0 / 76.0$ & $-52 \%$
\end{tabular}

[a] "Cumulated" e.e. in 1-(4-nitrophenyl)ethanol (determined from the aliquots) for the different run, full conversion for each run. [b] "Cumulated" equivalents in $(R)$ and $(S)$ 1-(4-nitrophenyl)ethanol for the different run (100 mol\% of 1-(4nitrophenyl)ethanone is converted by run).

GC analyses From the aliquots of the different run.

\section{Tables S.3, run 1:}

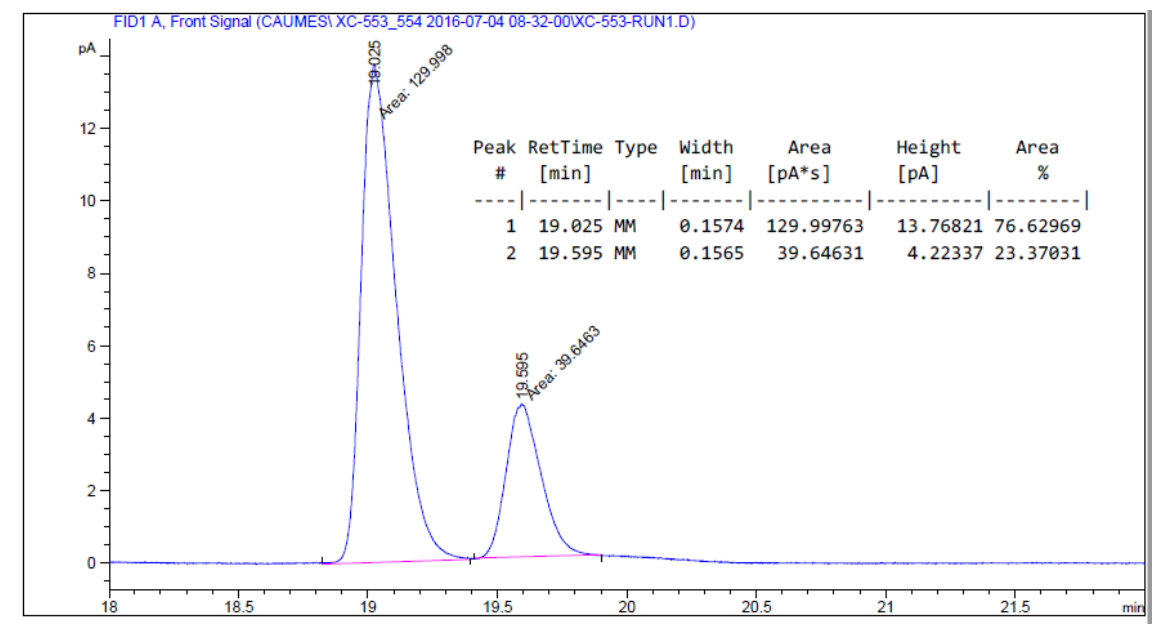

Tables S.3, run 2:

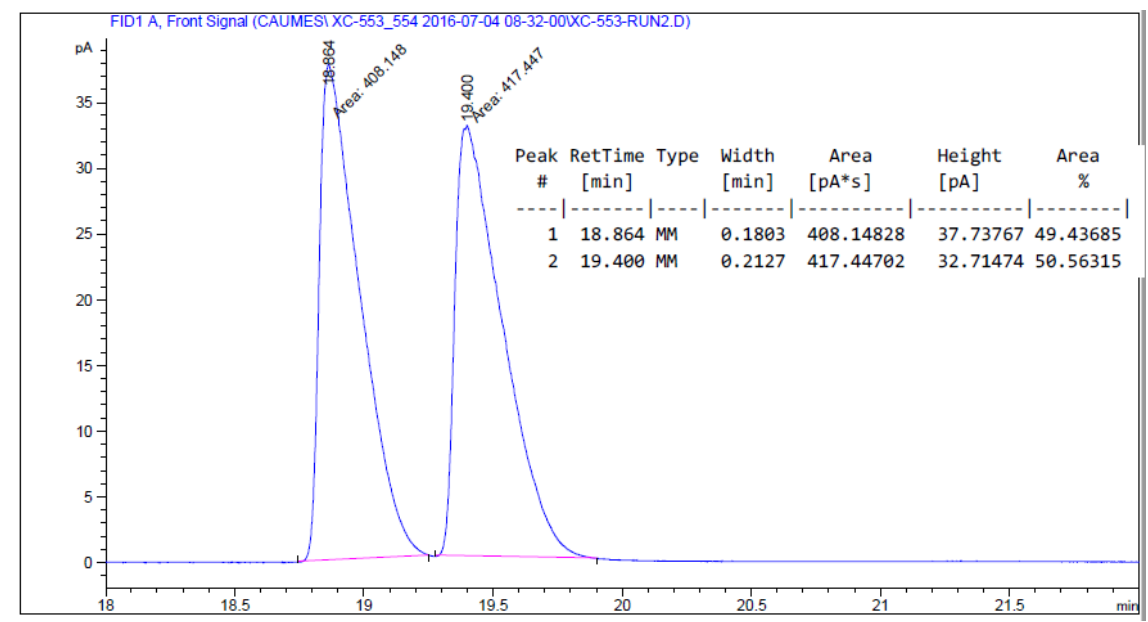


Tables S.3, run 3:

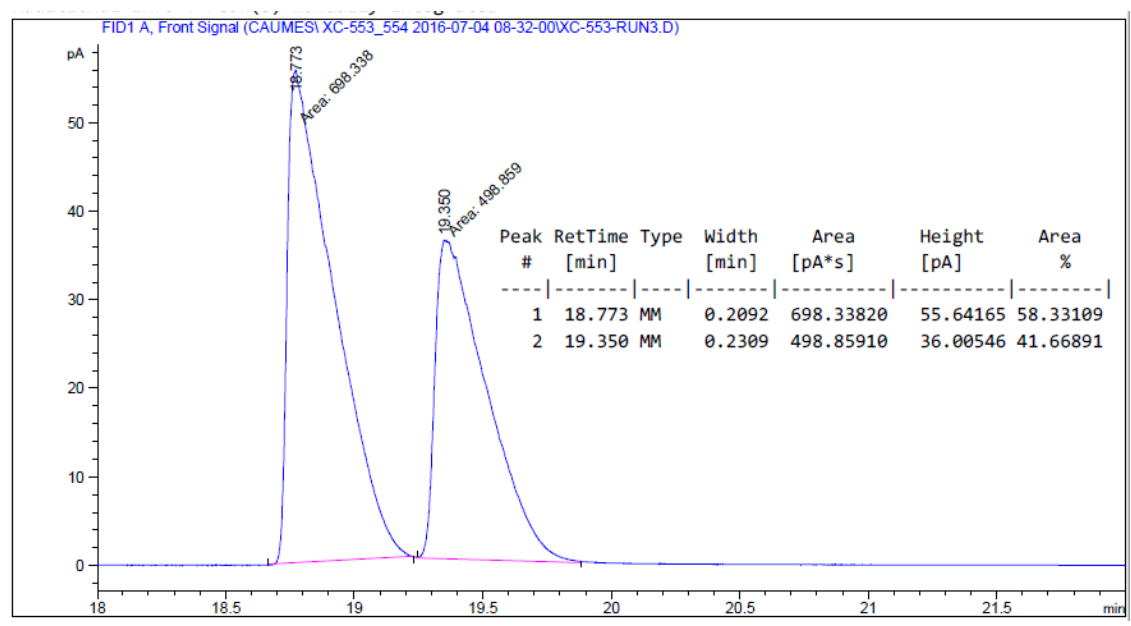

Tables S.3, run 4:

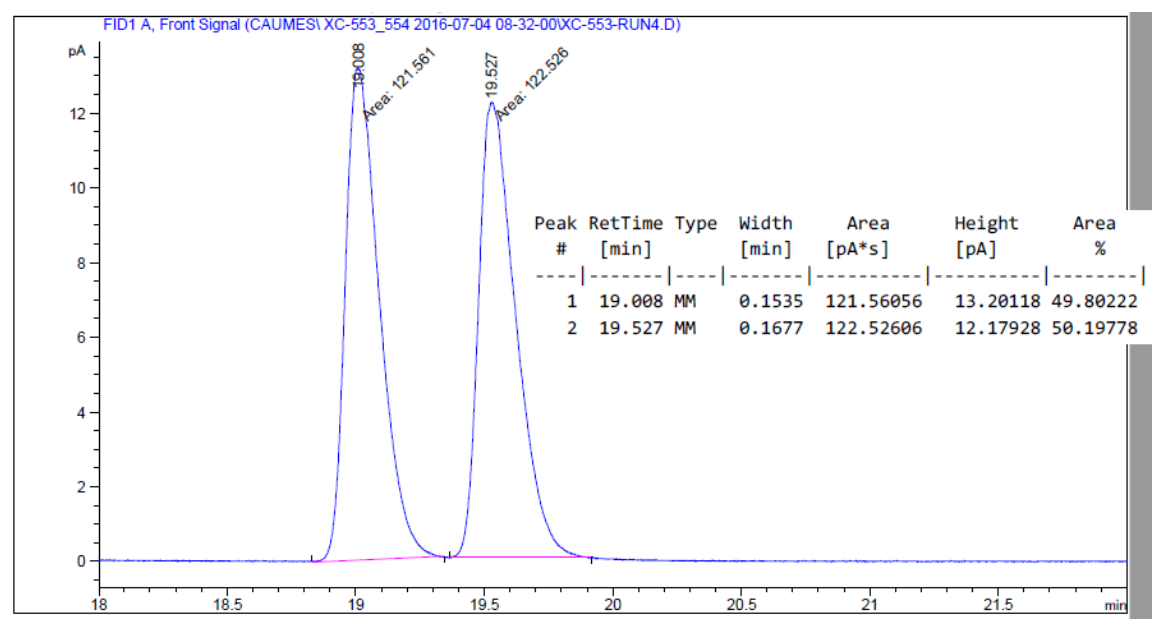

Determination of the time required for the stereochemical switch (Table S.4): A test tube was loaded with $\mathrm{Cu}(\mathrm{OAc})_{2} \cdot \mathrm{H}_{2} \mathrm{O}$ (1.0 mg, $\left.3.0 \mathrm{~mol} \%\right)$ and BTA ${ }^{\mathbf{P P h} 2}$ (6.9 mg, $6.0 \mathrm{~mol} \%$ ) in dry THF (500 $\mu \mathrm{L}$ ) and the mixture was stirred for 30 minutes. The solvent was removed under vacuum and the test tube was further put under vacuum $\left(1.10^{-3} \mathrm{mbar}\right)$ for 1 hour. Then 1-(4nitrophenyl)ethanone (28.0 mg, $0.17 \mathrm{mmol}$ ) was added before flushing the tube with argon for 10 seconds. BTA (R)-Cha (8.6 mg, $4.4 \mathrm{~mol} \%)$ and BTA (S)-Cha (17.2 mg, $8.7 \mathrm{~mol} \%)$ in 80 $\mu \mathrm{L}$ of dry toluene was added to the test tube as well as dry toluene in order to get a total volume of $590 \mu \mathrm{L}$. The mixture was stirred for $15 \mathrm{~min}$ at room temperature. The mixture was cooled to $0{ }^{\circ} \mathrm{C}$ and further stirred for $15 \mathrm{~min}$. BTA (R)-Cha (25.4 mg, $13.0 \mathrm{~mol} \%$ ) in $200 \mu \mathrm{L}$ of toluene was added as well as $\mathrm{PhSiH}_{3}(21.0 \mu \mathrm{L}, 0.17 \mathrm{mmol})$ after a measured time. The mixture was stirred for 10 minutes and the typical work-up procedure was followed. 


\section{GC analyses}

Tables S.4, no switch: $+60 \%$ e.e.(R)

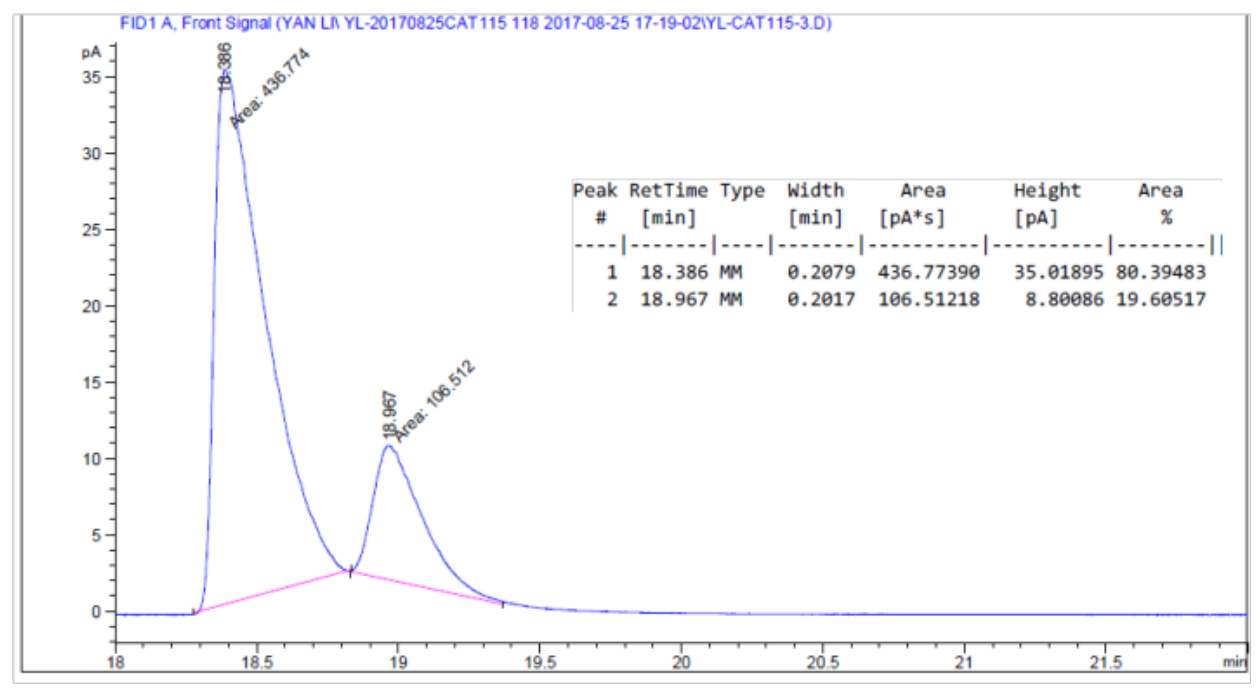

Tables S.4, entry 2 (5 seconds): $-56 \%$ e.e.(S)

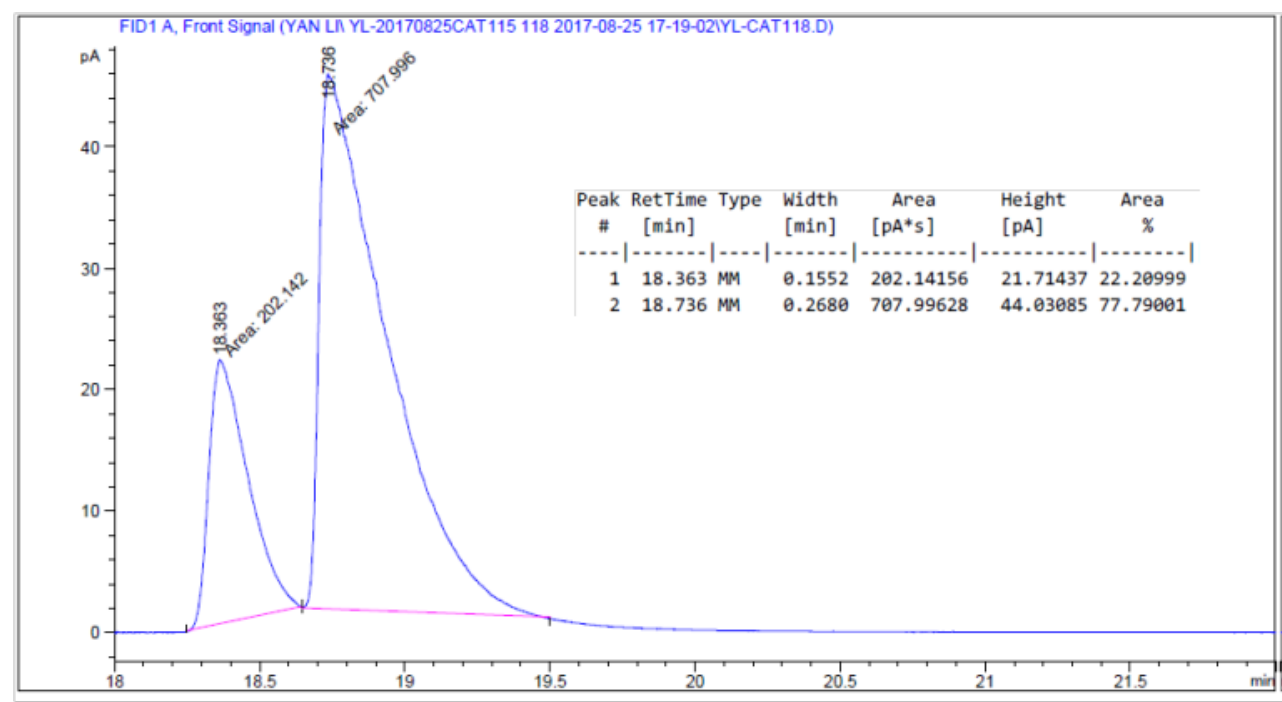


Stereochemical switch during the conversion of 1-(4-biphenylyl)ethanone (Scheme S.1a): A test tube was loaded with $\mathrm{Cu}(\mathrm{OAc})_{2} \cdot \mathrm{H}_{2} \mathrm{O}(1.0 \mathrm{mg}, 3.0 \mathrm{~mol} \%)$ and $\mathbf{B T A}{ }^{\mathbf{P P h} 2}(6.9 \mathrm{mg}, 6.0$ mol\%) in dry THF (500 $\mu \mathrm{L})$ and the mixture was stirred for 30 minutes. The solvent was removed under vacuum and the test tube was further put under vacuum $\left(1.10^{-3} \mathrm{mbar}\right)$ for 1 hour. Then 1-(4-biphenylyl)ethanone (34.0 $\mathrm{mg}, 0.17 \mathrm{mmol}$ ) was added before flushing the tube with argon for 10 seconds. BTA (R)-Cha (8.6 mg, $4.4 \mathrm{~mol} \%)$ and BTA (S)-Cha (17.2 $\mathrm{mg}, 8.7 \mathrm{~mol} \%$ ) in $80 \mu \mathrm{L}$ of dry toluene was added to the test tube as well as dry toluene in order to get a total volume of $590 \mu \mathrm{L}$. The mixture was stirred for $15 \mathrm{~min}$ at room temperature. The mixture was cooled to $0{ }^{\circ} \mathrm{C}$ and further stirred for $15 \mathrm{~min}$. Then, a solution of toluene (200 $\mu \mathrm{L})$ containing BTA (R)-Cha $(25.4 \mathrm{mg}, 13.0 \mathrm{~mol} \%)$ and $\mathrm{PhSiH}_{3}(21.0 \mu \mathrm{L}$, $0.17 \mathrm{mmol}$ ) was added. The mixture was stirred for $3 \mathrm{~h}$ and the typical work-up procedure was followed.

\section{HPLC analyses}

Scheme S.1a, no switch: + 34\% e.e.(R)

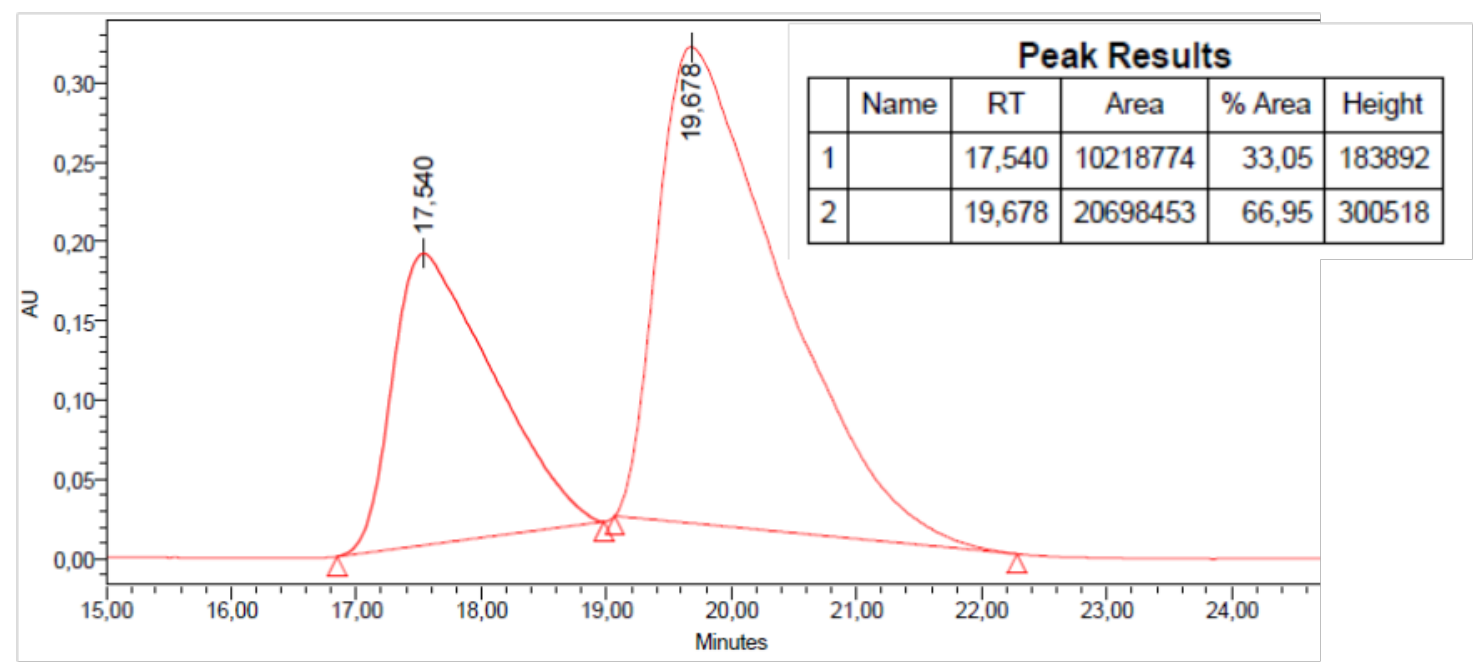


Scheme S.1a, switch: - 43\% e.e.(S)

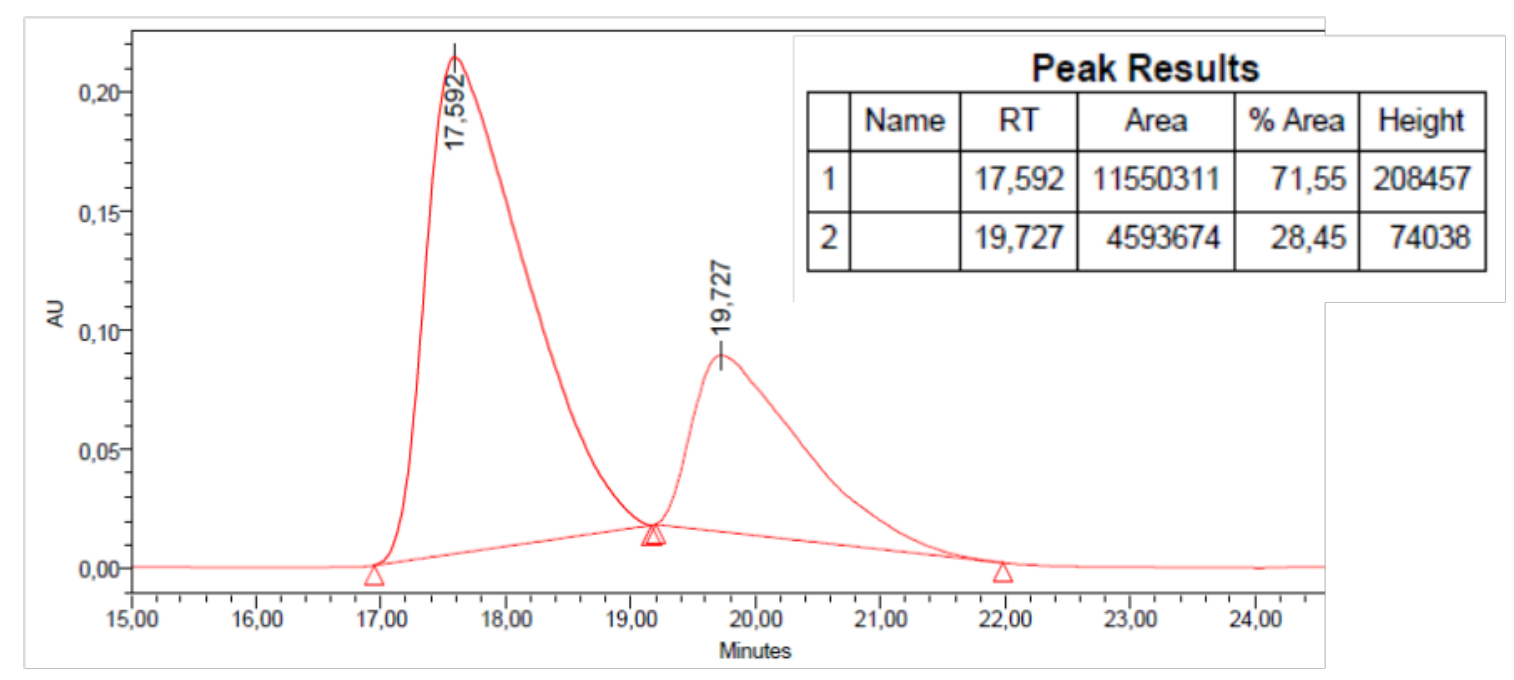

Stereochemical switch during the conversion of 1-(4-biphenylyl)ethanone (Scheme S.1b): A test tube was loaded with $\mathrm{Cu}(\mathrm{OAc})_{2} \cdot \mathrm{H}_{2} \mathrm{O}(1.0 \mathrm{mg}, 3.0 \mathrm{~mol} \%)$ and $\mathbf{B T A}^{\mathbf{P P h} 2}$ (6.9 mg, 6.0 mol\%) in dry THF (500 $\mu \mathrm{L})$ and the mixture was stirred for 30 minutes. The solvent was removed under vacuum and the test tube was further put under vacuum $\left(1.10^{-3} \mathrm{mbar}\right)$ for 1 hour. Then 1-(4-biphenylyl)ethanone (34.0 mg, $0.17 \mathrm{mmol}$ ) was added before flushing the tube with argon for 10 seconds. BTA (R)-Cha (2.6 mg, $1.3 \mathrm{~mol} \%)$ and BTA (S)-Cha (10.3 mg, $5.3 \mathrm{~mol} \%$ ) in $80 \mu \mathrm{L}$ of dry toluene was added to the test tube as well as dry toluene in order to get a total volume of $590 \mu \mathrm{L}$. The mixture was stirred for $15 \mathrm{~min}$ at room temperature. The mixture was cooled to $-25^{\circ} \mathrm{C}$ and further stirred for $15 \mathrm{~min}$ and then $\mathrm{PhSiH}_{3}$ (21.0 $\mu \mathrm{L}, 0.17 \mathrm{mmol}$ ) was added. The mixture was stirred for 30 minutes, an aliquot was taken up and hydrolyzed (step 1) and BTA (R)-Cha (38.9 mg, $20.0 \mathrm{~mol} \%$ ) in $200 \mu \mathrm{L}$ of toluene was added. The reaction mixture was stirred overnight and the typical work-up procedure was followed (step 2). 
HPLC analyses

Scheme S.1b, aliquot (step 1): $+40 \%$ e.e. (R)

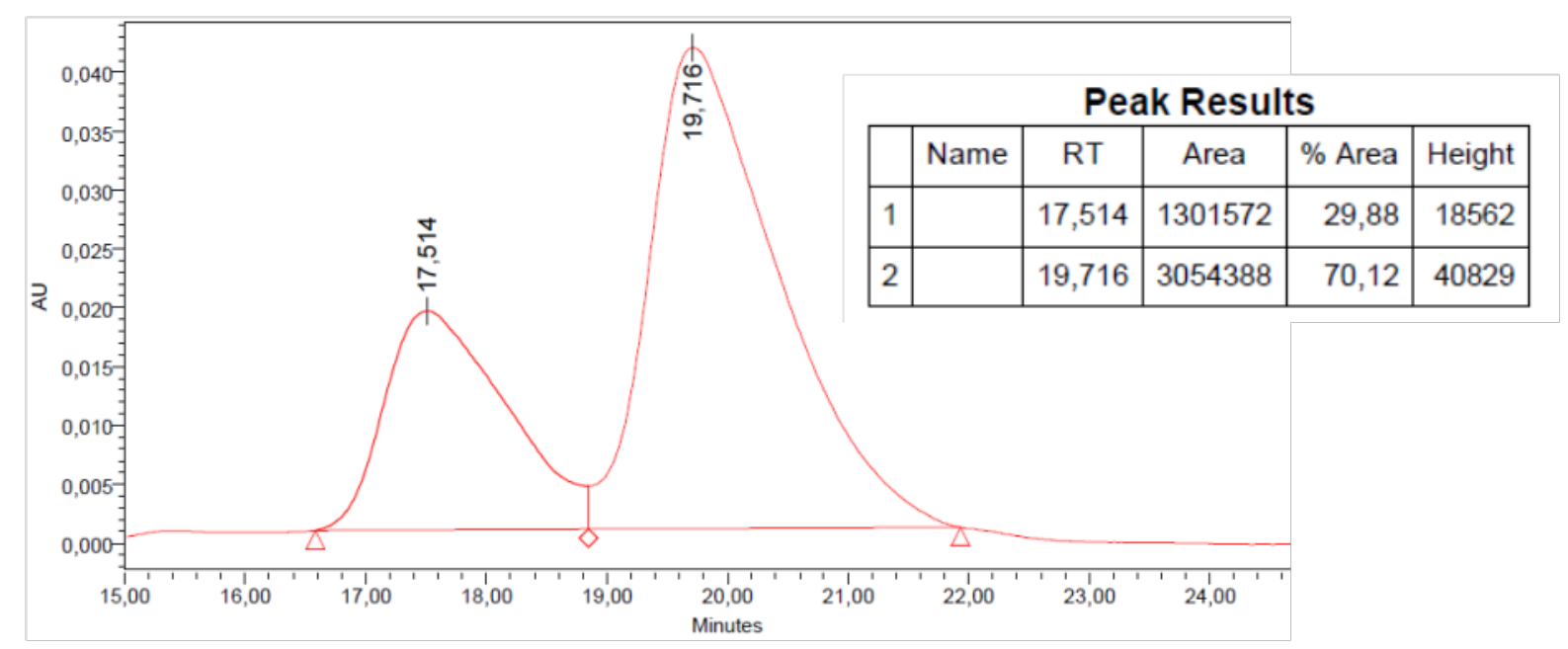

Scheme S.1b, final: -27\% e.e (S)

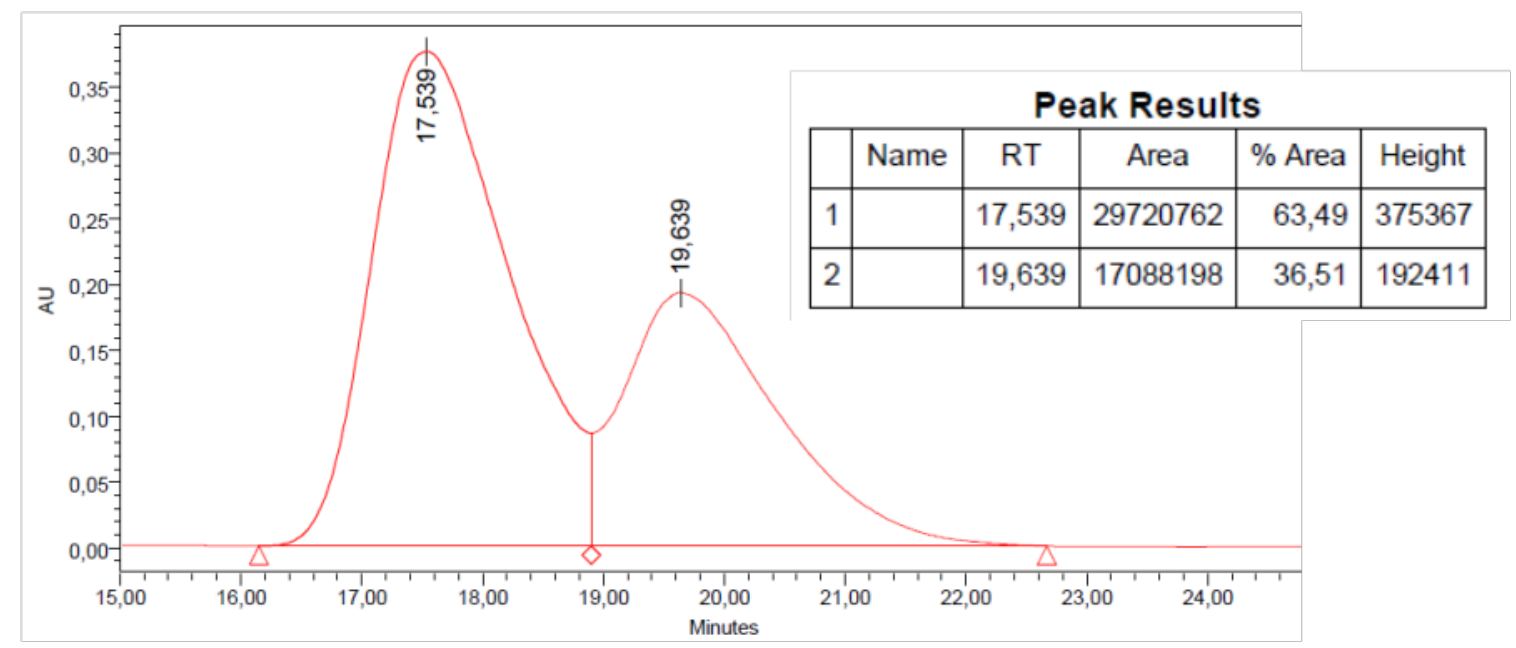


Copper-catalysed hydrosilylation of 1:1 mixture of 1-(4-nitrophenyl)ethanone and 1-(4biphenylyl)ethanone (Table S.5, Figure 1c): A Schlenk tube was loaded with $\mathrm{Cu}(\mathrm{OAc})_{2} \cdot \mathrm{H}_{2} \mathrm{O}$ (1.0 mg, $3.0 \mathrm{~mol} \%$ ) and $\mathbf{B T A}^{\mathbf{P P h}}(6.9 \mathrm{mg}, 6.0 \mathrm{~mol} \%)$ in dry THF (500 $\left.\mu \mathrm{L}\right)$ and the mixture was stirred for 30 minutes. The solvent was removed under vacuum and the Schlenk tube was further put under vacuum $\left(1.10^{-3} \mathrm{mbar}\right)$ for 1 hour. 1-(4-nitrophenyl)ethanone (28.0 mg, 0.17 mmol) and 1-(4-biphenylyl)ethanone $(34.0 \mathrm{mg}, 0.17 \mathrm{mmol})$ were added before flushing the Schlenk tube with argon for 10 seconds. BTA (R)-Cha (2.6 mg, $1.3 \mathrm{~mol} \%)$ and BTA (S)-Cha (10.3 mg, $5.3 \mathrm{~mol} \%$ ) in $200 \mu \mathrm{L}$ of dry toluene was added to the Schlenk tube as well as dry toluene in order to get a total volume of $590 \mu \mathrm{L}$. The mixture was stirred for $15 \mathrm{~min}$ at room temperature. The mixture was cooled to $-25{ }^{\circ} \mathrm{C}$ and further stirred for $15 \mathrm{~min}$ and then $\mathrm{PhSiH}_{3}$ (42.0 $\mu \mathrm{L}, 0.34 \mathrm{mmol}$ ) was added. The mixture was stirred for 2 minutes (step 1) and then BTA (R)-Cha (38.9 mg, $20.0 \mathrm{~mol} \%$ ) in $200 \mu \mathrm{L}$ of toluene was added. The reaction mixture was stirred for $12 \mathrm{~h}$ (step 2) and the typical work-up procedure was followed. 
GC analyses. GC analyses below have been performed under conditions for which the enantiomers of 1-(4-nitrophenyl)ethanol and 1-(4-biphenylyl)ethanol are not perfectly separated, yet it indicated the configuration of the major enantiomer obtained and was thus a good demonstration of the success of the selectivity switch. The enantiomeric excesses (indicated above peaks) were precisely measured using adequate separation conditions for 1-(4-nitrophenyl)ethanol and 1-(4-biphenylyl)ethanol (page S.18). The peak at 26.8 min corresponds to 1-(4-biphenylyl)ethanone.

\section{Table S.5, entry 1:}

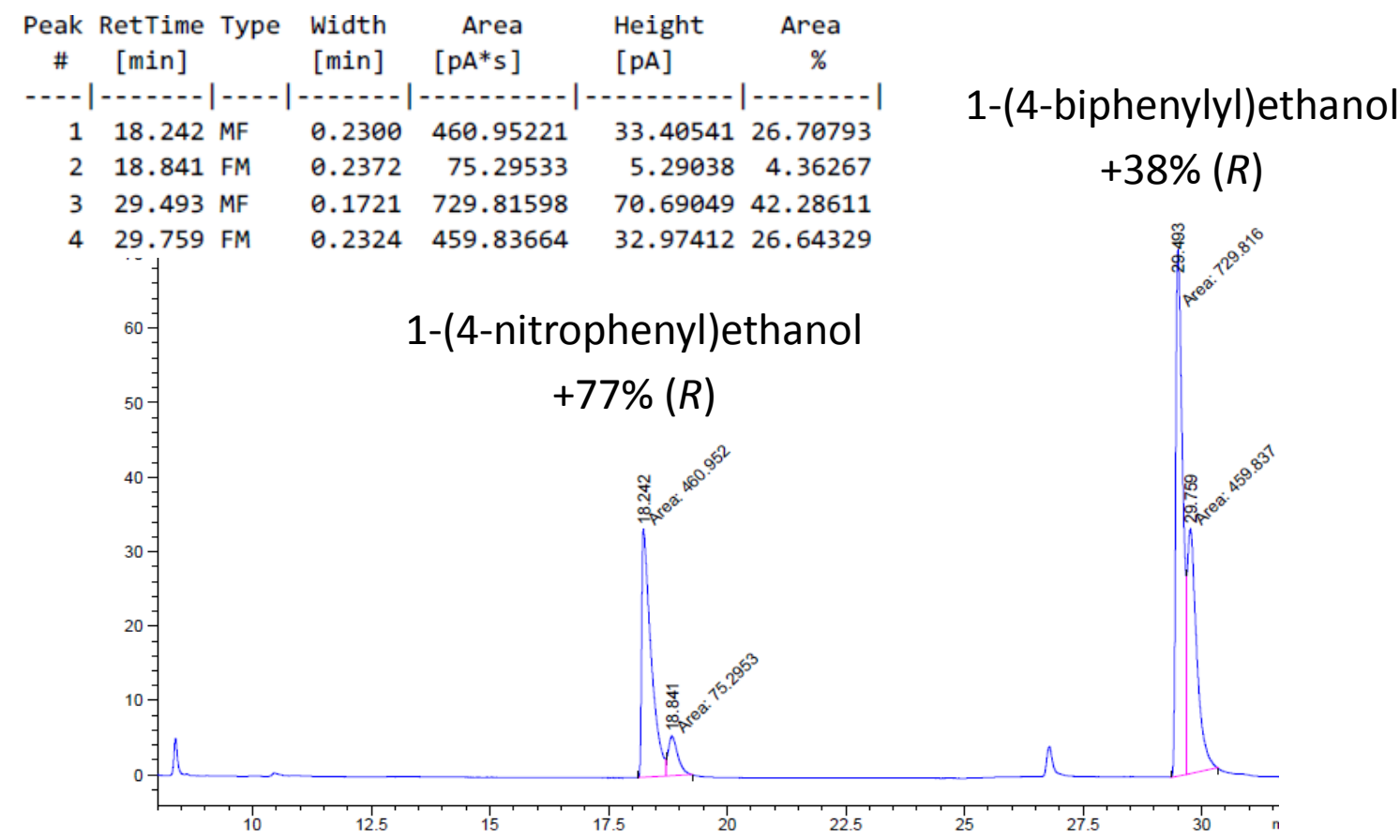

Table S.5, entry 2:

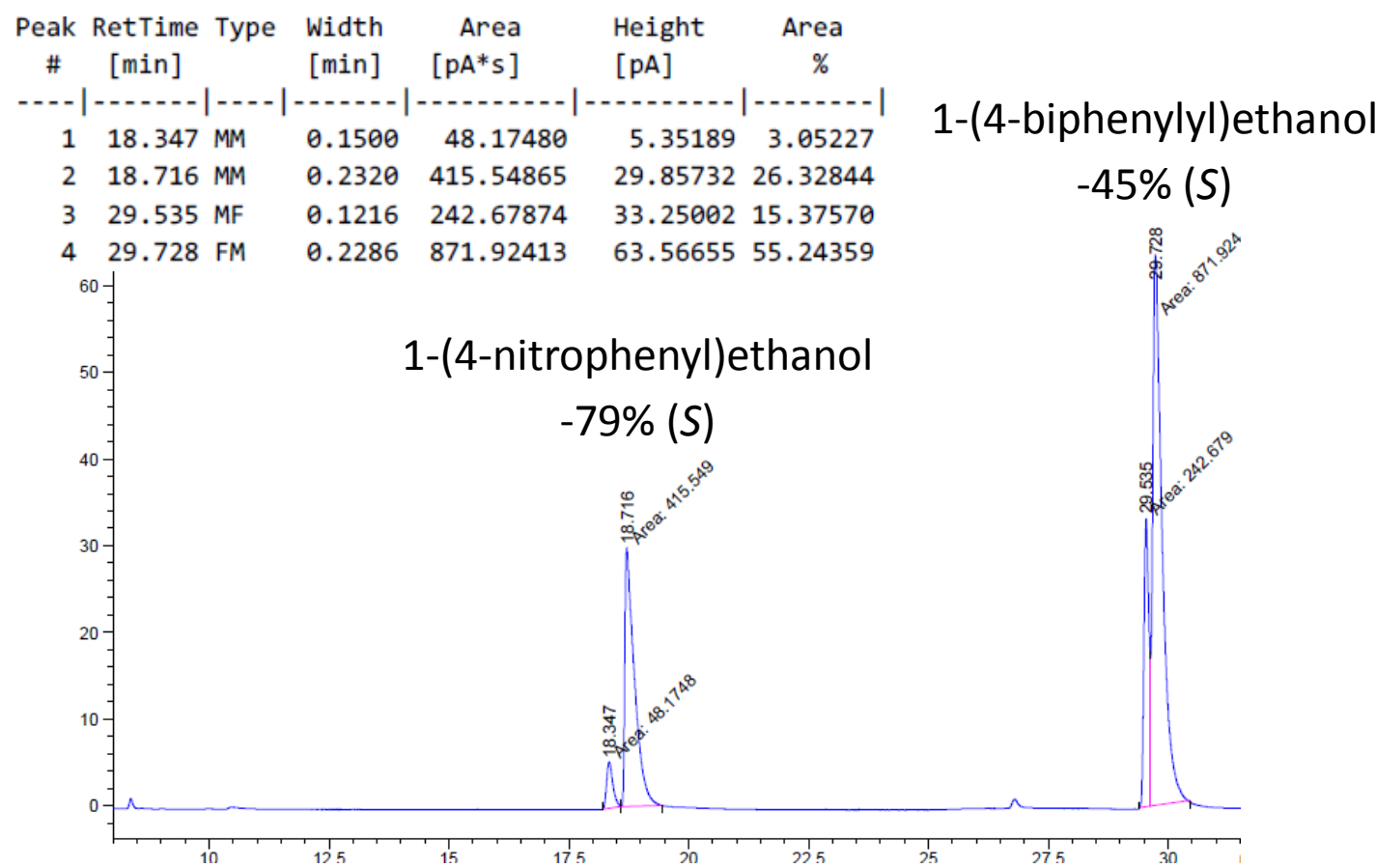


Table S.5, entry 3:

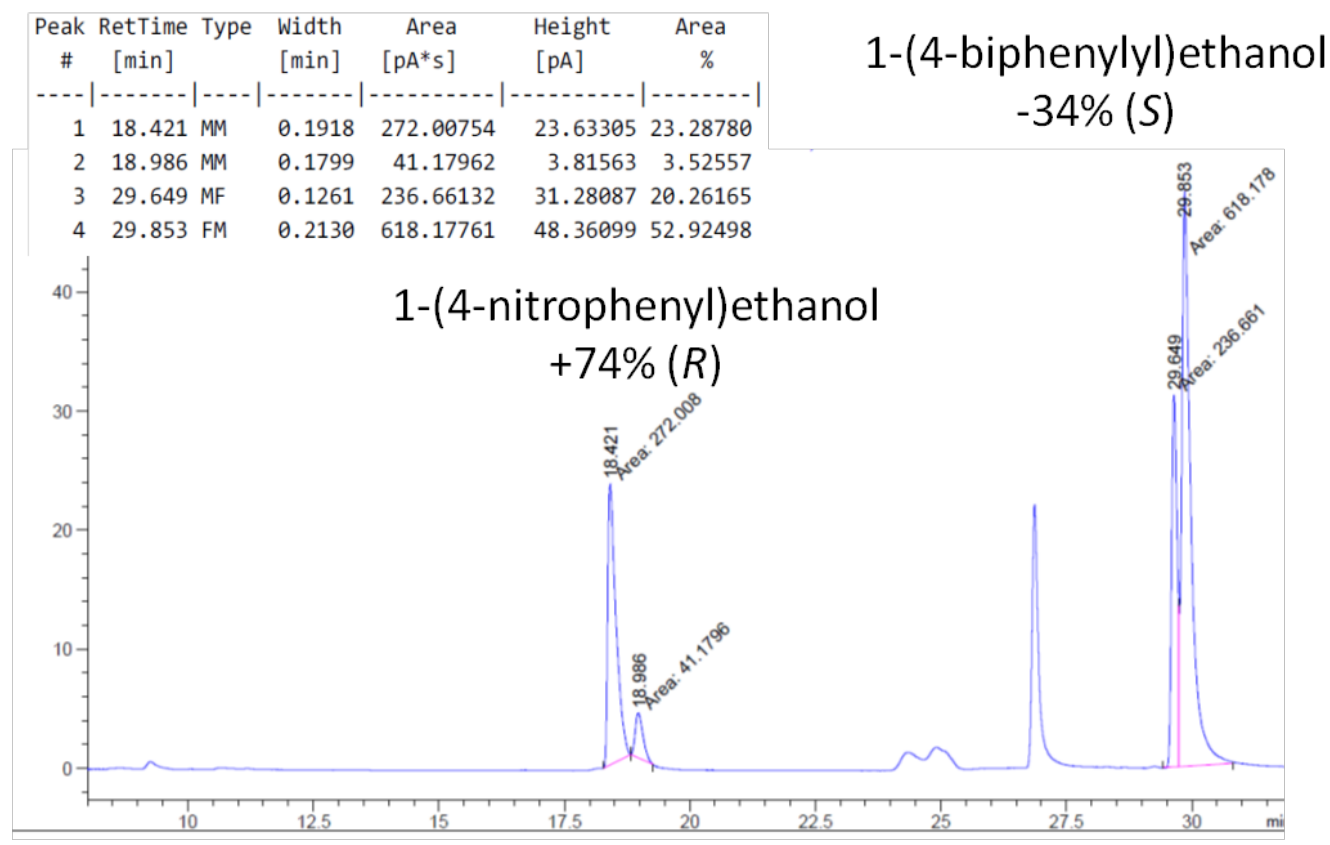

Table S.5, entry 4:

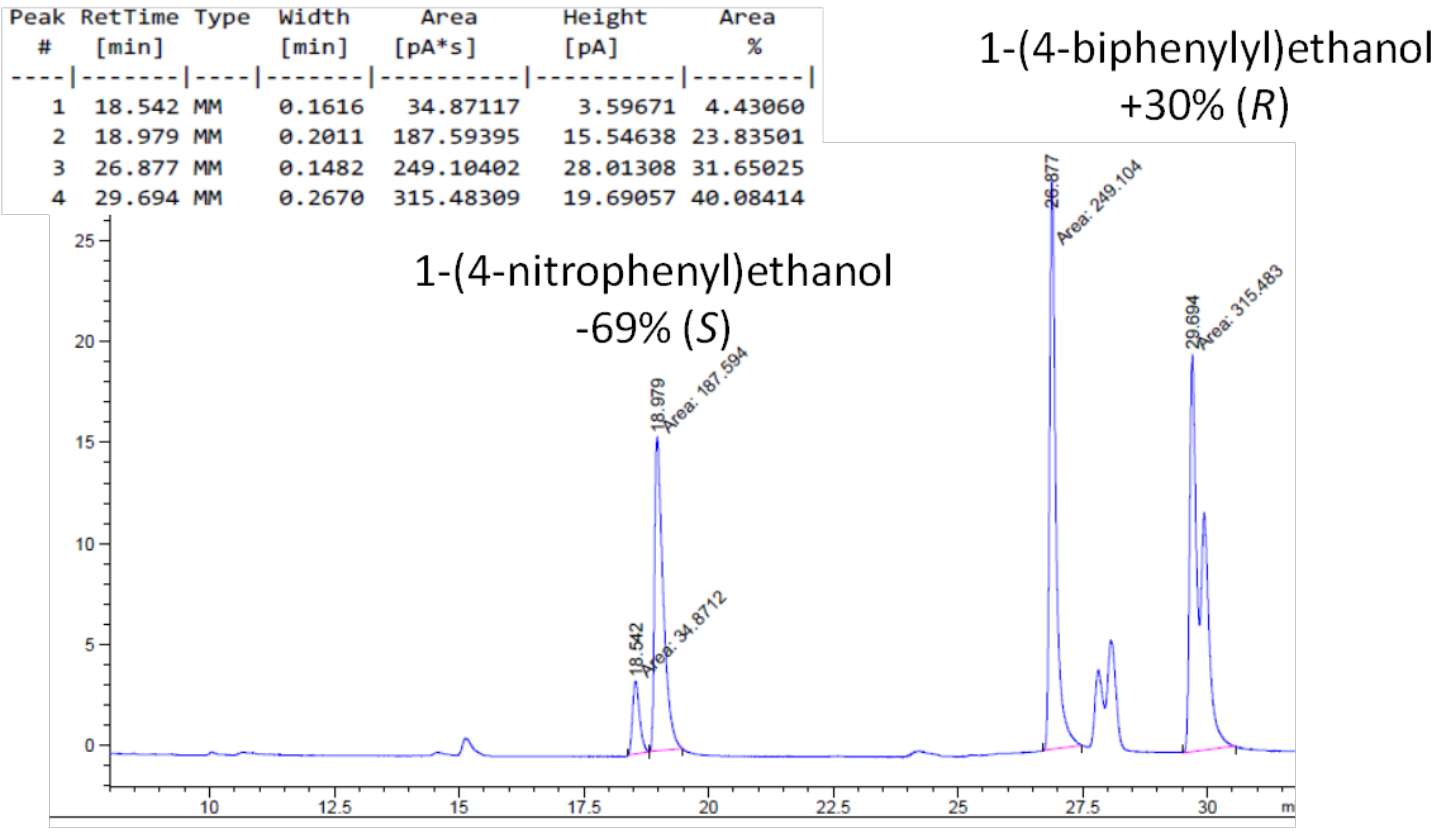


BTA $^{\text {PPh2 }}$

\section{${ }^{1} \mathrm{H}$ (DMSO-d6):}

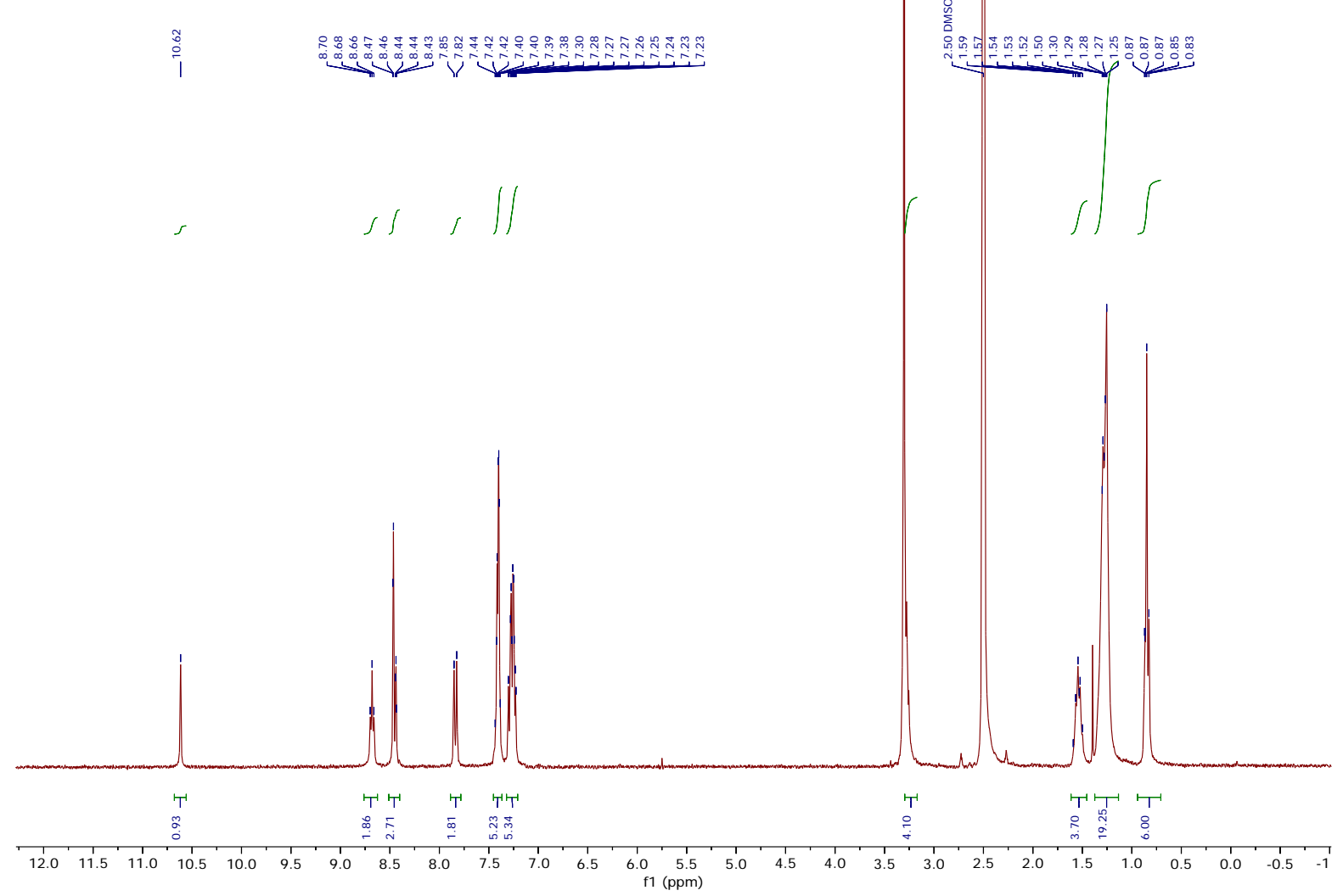

${ }^{31} \mathrm{P}\left\{{ }^{1} \mathrm{H}\right\}($ DMSO-d 6$):$

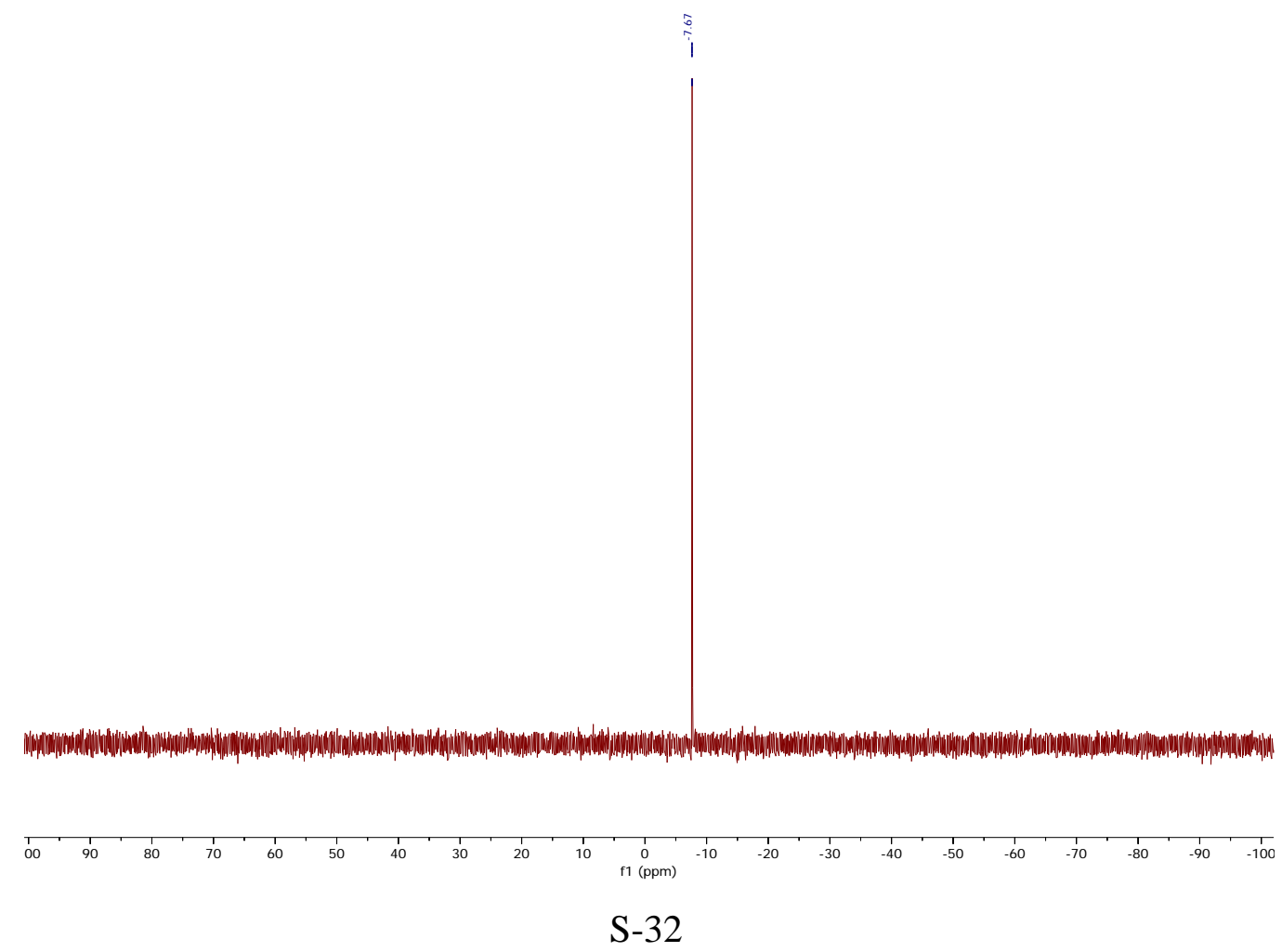


${ }^{13} \mathrm{C}\left\{{ }^{1} \mathrm{H}\right\}$ (DMSO-d $\mathrm{d}_{6}$ ):

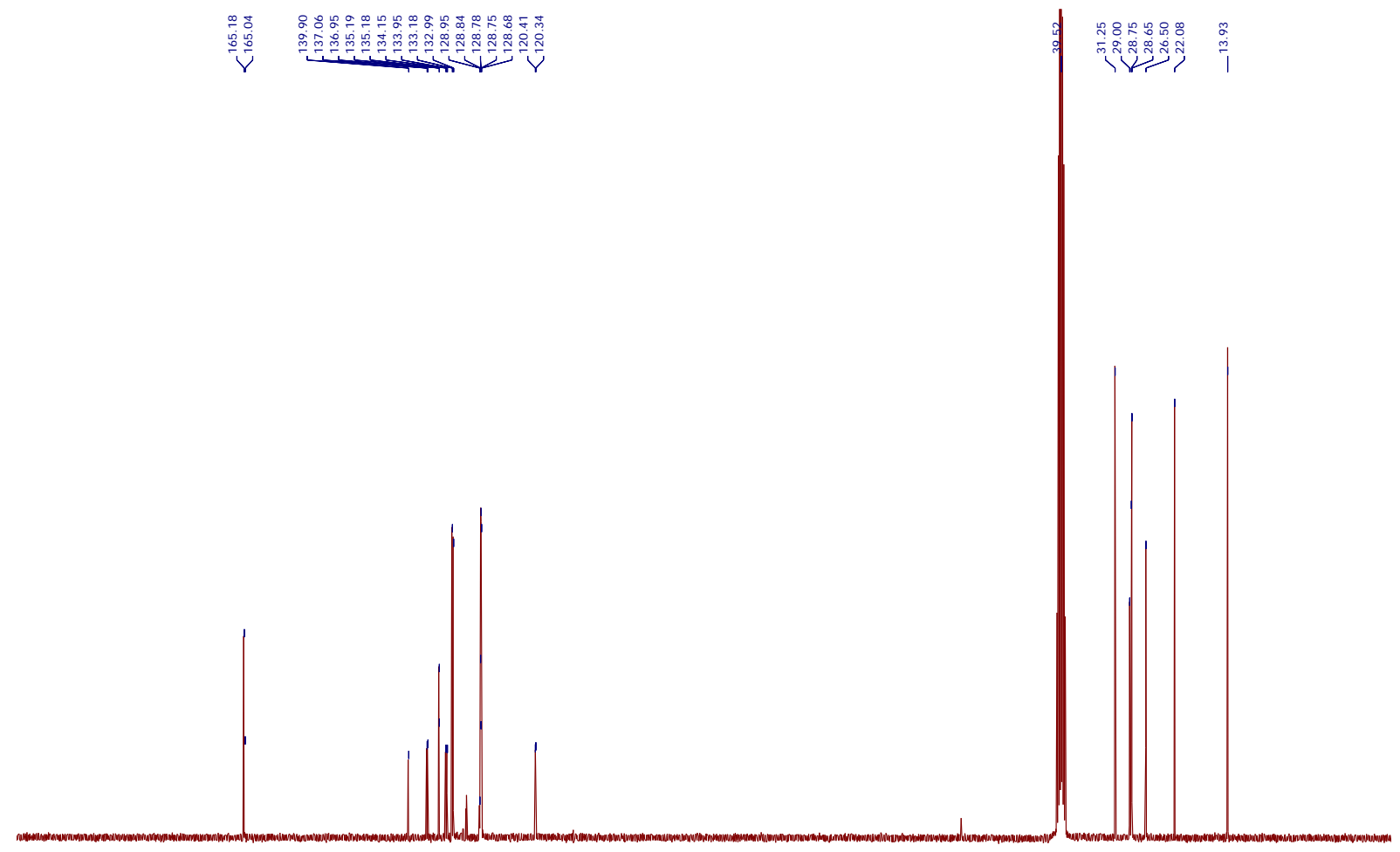

\begin{tabular}{llllllllllllllllllllllll}
\hline 50 & 190 & 180 & 170 & 160 & 150 & 140 & 130 & 120 & 110 & 100 & 90 & 80 & 70 & 60 & 50 & 40 & 30 & 20 & 10 & 0 & -10
\end{tabular} 


\section{References:}

[1] V. Simic, L. Bouteiller, M. Jalabert, J. Am. Chem. Soc. 2003, 125, 13148-13154.

[2] T. F. A. De Greef, M. M. J. Smulders, M. Wolffs, A. P. H. J. Schenning, R. P. Sijbesma, E. W. Meijer, Chem. Rev. 2009, 109, 5687-5754.

[3] a) A. Desmarchelier, M. Raynal, P. Brocorens, N. Vanthuyne, L. Bouteiller, Chem. Commun. 2015, 51, 7397-7400; b) A. Desmarchelier, B. Giordano Alvarenga, X. Caumes, L. Dubreucq, C. Troufflard, M. Tessier, N. Vanthuyne, J. Idé, T. Maistriaux, D. Beljonne, P. Brocorens, R. Lazzaroni, M. Raynal, L. Bouteiller, Soft Matter 2016, 12, 7824-7838; c) X. Caumes, A. Baldi, G. Gontard, P. Brocorens, R. Lazzaroni, N. Vanthuyne, C. Troufflard, M. Raynal, L. Bouteiller, Chem. Commun. 2016, 52, 13369-13372.

[4] A. Desmarchelier, X. Caumes, M. Raynal, A. Vidal-Ferran, P. W. N. M. van Leeuwen, L. Bouteiller, J. Am. Chem. Soc. 2016, 138, 4908-4916.

[5] S. Allenmark, Chirality 2003, 15, 409-422.

[6] J. Roosma, T. Mes, P. Leclère, A. R. A. Palmans, E. W. Meijer, J. Am. Chem. Soc. 2008, 130, 1120-1121.

[7] D. Gelman, L. Jiang, S. L. Buchwald, Org. Lett. 2003, 5, 2315-2318.

[8] G. Uray, W. Stampfer, W. M. F. Fabian, J. Chromatogr. A 2003, 992, 151-157.

[9] K. Junge, B. Wendt, D. Addis, S. L. Zhou, S. Das, M. Beller, Chem. Eur. J. 2010, 16, 68-73. 